\title{
HvWRKY10, HvWRKY19, and HvWRKY28 Regulate Mla-Triggered Immunity and Basal Defense to Barley Powdery Mildew
}

\author{
Yan Meng ${ }^{1}$ and Roger P. Wise ${ }^{1,2}$ \\ ${ }^{1}$ Department of Plant Pathology and Microbiology, Center for Plant Responses to Environmental Stresses, lowa State \\ University, Ames, IA 50011-1020, U.S.A.; ${ }^{2}$ Crop and Insect Genetics, Genomics, and Informatics Research Unit (CIGGIR), \\ United States Department of Agriculture-Agricultural Research Service, lowa State University
}

Submitted 11 April 2012. Accepted 12 July 2012.

WRKY proteins represent a large family of transcription factors (TF), involved in plant development and defense. In all, 60 unique barley TF have been annotated that contain the WRKY domain; 26 of these are represented on the Barley1 GeneChip. Time-course expression profiles of these 26 HvWRKY TF were analyzed to investigate their role in mildew locus a (Mla)-mediated immunity to Blumeria graminis f. sp. hordei, causal agent of powdery mildew disease. Inoculation-responsive, Mla-specified interactions with B. graminis f. sp. hordei revealed that $12 \mathrm{HvWRKY}$ were differentially expressed: 10 highly upregulated and two significantly downregulated. Barley stripe mosaic virus-induced gene silencing of HvWRKY10, HvWRKY19, and HvWRKY28 compromised resistance-gene-mediated defense to powdery mildew in genotypes harboring both Rarl-dependent and Rarl-independent Mla alleles, indicating that these WRKY TF play key roles in effector-triggered immunity. Comprehensive yeast two-hybrid analyses, however, did not reveal a direct interaction between these three nuclear-localized WRKY TF and MLA. Transient overexpression of all three WRKY TF in single cells expressing Mlo, which encodes a negative regulator of penetration resistance, significantly decreased susceptibility. Taken together, these loss- and gain-of-function studies demonstrate that HvWRKY10, HvWRKY19, and HvWRKY28 positively regulate the barley transcriptome in response to invasion by $B$. graminis $f$. sp. hordei.

Nucleotide sequence data for HvWRKY48, HvWRKY49, HvWRKY53, HvWRKY55, and HvWRKY61 are available in the GenBank database under accession numbers JQ806389, JQ806390, JQ806391, JQ806392, and JX216840, respectively. Microarray data are available as PLEXdb datasets BB2 (ArrayExpress E-TABM-82) and BB10 (ArrayExpress E-TABM-142).

Mention of trade names or commercial products in this publication is solely for the purpose of providing specific information and does not imply recommendation or endorsement by the United States Department of Agriculture.

Corresponding author: R. P. Wise;

Fax: +1.515.294.9420; E-mail: rpwise@ iastate.edu

* The $\boldsymbol{e}$-Xtra logo stands for "electronic extra" and indicates that one supplementary table is published online.

This article is in the public domain and not copyrightable. It may be freely reprinted with customary crediting of the source. The American Phytopathological Society, 2012.
Plants have evolved a complex regulatory system to temporally and spatially manipulate response to disease and environmental stress. Transcriptional reprogramming of gene expression is a crucial part of this regulatory process (Chen et al. 2002; Singh et al. 2002). To achieve this, a significant portion of a genome's capacity is dedicated to the regulation of transcription; for example, over 5\% of the Arabidopsis (Arabidopsis thaliana) genome encodes greater than 1,500 transcription factors (TF) (Riechmann et al. 2000). Plants deploy this vast $\mathrm{TF}$ network to rapidly and effectively limit the growth of pathogens by cell death at and surrounding the infection site or to regulate basal defense to avoid unnecessary damage because only harmless or helpful molecules are recognized (Dangl 2007).

The WRKY family of TF comprises 74 members in Arabidopsis and 109 members in rice (Oryza sativa) (Eulgem and Somssich 2007; Mao et al. 2007). The existence of one or two WRKY domains is the main feature of WRKY proteins, which are approximately 60 amino acids long, containing a conserved motif of WRKYGQK or its variants at the $\mathrm{N}$ terminus and a zinc finger motif $\left(\mathrm{CX}_{4-7} \mathrm{CX}_{22-23} \mathrm{HXH} / \mathrm{C}\right)$ at the $\mathrm{C}$ terminus. Based on the number of WRKY domains and particular features of zinc-finger motif, the WRKY family has been classified into three groups (I, II, and III). Group II has been further divided into five subgroups (IIa to IIe), which are classified according to additional short conserved structural motifs (Wu et al. 2005). To carry out its regulatory function, the WRKY domain generally binds to a W-box in the promoter region of its target gene, a DNA-element with the consensus sequence of $(\mathrm{C} / \mathrm{T}) \mathrm{TGAC}(\mathrm{C} / \mathrm{T})$. W-boxes have been found in the promoter or the $5^{\prime}$ untranslated regions of many target genes involved in plant disease defense, abiotic stress, and seed development as well as leaf senescence (Yu et al. 2001).

WRKY proteins play essential roles in the transcriptional regulation of innate immunity. Gain- or loss-of-function experiments illustrate that many WRKY proteins are key regulators of two interdependent branches of the plant immune system: pathogen-associated molecular pattern (PAMP)-triggered immunity (PTI) and effector-triggered immunity (ETI) (Bhattarai et al. 2010; Chen et al. 2010; Peng et al. 2008; Xing et al. 2008). In recent years, such studies have been extended from model plants (e.g., Arabidopsis) to crop species (Dellagi et al. 2000; Park et al. 2006). A recent study in soybean revealed that three novel WRKY TF (GmWRKY36, GmWRKY40, and GmWRKY45) are involved in regulating Rpp2-mediated resistance response to Asian soybean rust Phakopsora pachyrhizi. Rpp2-mediated resistance was compromised when these 
three $W R K Y$ genes were silenced individually via Bean pod mottle virus-induced gene silencing (Pandey et al. 2011). In rice, OsWRKY13 is involved in the regulation of resistance to bacteria blight and the rice blast fungus, Magnaporthe grisea (Qiu et al. 2007). Additionally, OsWRKY31 and OsWRKY45 are also implicated in resistance to rice blast (Tao et al. 2009; Zhang et al. 2008a). OsWRKY71 regulates rice resistance to the bacteria pathogen Xanthomonas oryzae, and overexpression of OsWRKY71 results in an enhanced resistance response (Liu et al. 2007). Further, tomato SIWRKY72 contributes to basal defense against root-knot nematodes and potato aphids, as well as $\mathrm{Mi}$-1-mediated gene-for-gene resistance to these pests (Bhattarai et al. 2010).

In barley (Hordeum vulgare L.), mildew-resistance locus a (Mla) confers isolate-specific resistance to the powdery mildew Blumeria graminis f. sp. hordei, which requires the recognition of a corresponding effector (avirulence) protein in the cytoplasm. MLA was revealed to associate with HvWRKY1 and HvWRKY2, two negative regulators of PAMP-triggered basal defense in the nucleus; during this interaction, WRKY acts as a repressor to regulate resistance against $B$. graminis f. sp. hordei (Shen et al. 2007). Hence, this study indicates that WRKY genes are involved in mechanistically connecting and balancing PTI and ETI. HvWRKY1, also designated HvWRKY38 (Marè et al. 2004), likewise functions in transcriptional reprogramming of barley genes against cold and drought stresses, indicating its regulatory role in barley abiotic stress response.

Aside from HvWRKY1 and HvWRKY2, the functions of other $W R K Y$ genes in barley and powdery mildew interactions remain unclear. Bioinformatic data mining has shown that transcript accumulation of numerous HvWRKY genes are altered upon B. graminis f. sp. hordei infection (Mangelsen et al. 2008). However, to our knowledge, no detailed functional analysis has been published. In this report, we performed a comprehensive functional analysis of WRKY TF in barley. Loss- and gain-of-function studies indicate that HvWRKY10, HvWRKY19, and HvWRKY28 act as positive regulators in a multifaceted network to fine-tune the response of barley to $B$. graminis f. sp. hordei invasion.

\section{RESULTS}

\section{Informatic identification of HvWRKY TF.}

Based on early expressed sequence tag (EST) collections (Close et al. 2004), initial computational analysis identified 45 HvWRKY genes (Mangelsen et al. 2008). In recent years, however, sequencing of the 5.3-gigabase barley genome has made rapid progress (Mayer et al. 2011; Schulte et al. 2009); therefore, we undertook an effort to identify a more complete
HvWRKY gene family. Using the rice annotations described by Xie and associates (2005), we first used tBLASTn to interrogate all OsWRKY TF against HarvEST Barley Assembly 21, which contains the barley EST contigs used for probe set selection for the Barley1 GeneChip array (Close et al. 2004). In total, 74 nonredundant alignments were identified, of which 45 sequences represented 35 previously annotated HvWRKY genes (Mangelsen et al. 2008). The remaining 29 sequences were then further compared with the newly published 24,783 barley full-length cDNAs (Matsumoto et al. 2011) to obtain extended sequence information. As a result, 19 sequences were removed, because they did not include the WRKY signature domain. The 10 novel HvWRKY proteins all contain the conserved heptapeptide WRKYQGK or a slight variation, WKKYGQK. Additionally, these 10 additional WRKY proteins also possess the unique zinc-finger motif $\left(\mathrm{CX}_{4-7} \mathrm{CX}_{22-23} \mathrm{HXH} / \mathrm{C}\right)$, which is the second characteristic feature of WRKY proteins. These HvWRKY proteins were designated HvWRKY47 to HvWRKY56, respectively.

Similar strategies were used to compare the OsWRKY sequences to the more comprehensive HarvEST Barley Assembly 36 to complete the available $\operatorname{HvWRKY}$ gene set, beyond what was represented on the Barley1 GeneChip. Five additional HvWRKY proteins, HvWRKY57 to HvWRKY61, were identified that contained the conserved heptapeptide WRKY domain and the zinc-finger motif. HvWRKY47 to HvWRKY61 are presented in Table 1, along with their classifications into different groups or subgroups, and aligned to their predicted orthologs in the model monocot rice and dicot Arabidopsis.

\section{Experimental concept and design: Identification of B. graminis f. sp. hordei-responsive HvWRKY TF.}

In most cases, transcript accumulation will be affected by particular biotic and abiotic stresses, and the response pattern can be utilized to predict its functional contribution to the interaction (Caldo et al. 2004; Chen et al. 2002; Dong et al. 2003; Ramamoorthy et al. 2008; Ryu et al. 2006). We utilized a GeneChip-based approach, combined with a comprehensive set of fast neutron- and ethyl methane sulfonate-derived loss-of-function mla mutants (Meng et al. 2009; Moscou et al. $2011 \mathrm{Xi}$ et al. 2009; Zhou et al. 2001) to aid in the identification of $\mathrm{HvWRKY}$ genes that are differentially expressed in response to powdery mildew. Homozygous mla mutants manifest in a partially or fully susceptible phenotype to $B$. graminis f. sp. hordei isolate $5874\left(A V R_{a 1}, A V R_{a 6}\right.$, and $\left.A V R_{a 12}\right)$, however, display an otherwise normal growth habit.

In all, 26 of the 60 putative HvWRKY TF are represented by probe sets on the $22 \mathrm{~K}$ Barley1 GeneChip (Table 2), including four of the newly annotated HvWRKY TF listed in Table 1.

Table 1. Newly identified HvWRKY transcription factors and their putative orthologs in Arabidopsis and rice

\begin{tabular}{|c|c|c|c|c|}
\hline Gene number & Accession number & WRKY group & AtWRKY ortholog & OsWRKY ortholog ${ }^{a}$ \\
\hline HvWRKY47 & AK364800 & $\mathrm{IIb}$ & 6,42 & 99 \\
\hline HvWRKY48 & JQ806389 & IIc & 71 & 60 \\
\hline HvWRKY49 & JQ806390 & III & 70 & 64 \\
\hline HvWRKY50 & AK357671 & I & 33 & 24 \\
\hline HvWRKY51 & AK366837 & IIc & 71 & 3 \\
\hline HvWRKY52 & AK368514 & IIa & $18,40,60$ & 71 \\
\hline HvWRKY53 & JQ806391 & III & 67 & 22 \\
\hline HvWRKY54 & AK368994 & IIe & 35 & 37 \\
\hline HvWRKY55 & JQ806392 & III & 30 & 19 \\
\hline HvWRKY56 & AK374747 & IId & 74 & * \\
\hline HvWRKY57 & AK250089 & I & 4 & 1 \\
\hline HvWRKY58 & AK248640 & IId & 39,74 & $*$ \\
\hline HvWRKY59 & AK376765 & I & 2 & $*$ \\
\hline HvWRKY60 & AK248555 & $\mathrm{IIb}$ & 72 & 73 \\
\hline HvWRKY61 & JX216840 & I & 3,4 & 1 \\
\hline
\end{tabular}

${ }^{a}$ Asterisk (*) indicates that ortholog could not be assigned with significance. 
We utilized these probe sets to interrogate Barley1 GeneChip datasets BB2 (ArrayExpress E-TABM-82) and BB10 (ArrayExpress E-TABM-142) (Caldo et al. 2006; Meng et al. 2009; Moscou et al. 2011) in PLEXdb (Dash et al. 2012). In the experiments represented by these two datasets, RNA was extracted from 7-day-old seedling first leaves (PO:0007094) harvested at $0,8,16,20,24$, and $32 \mathrm{~h}$ after inoculation (HAI) with $B$. graminis f. p. hordei isolate $5874\left(A V R_{a 6}\right)$ (Moscou et al. 2011). Noninoculated plants at these six time points were used as controls. The analysis presented here is based on six genotypes $\times$ six time points $\times$ two inoculation treatments $\times$ three biological replications for a total of 216 GeneChip hybridizations. False discovery rate (FDR) was calculated using the histogrambased technique as described by Nettleton and colleagues (2006). Using an FDR of $0.01 \%, 12$ of these HvWRKY probe sets exhibited significant differential expression between inoculated (INOC) and noninoculated (NON-INOC) plants for at least one time point among wild-type (CI 16137 [Mlal], CI 16151 [Mla6], and Sultan-5 [Mla12]) and loss-of-function (mla1-m508, mla6-m9472, and mla12-m66) mutants.

In total, 10 genes were highly induced upon pathogen infection (Figs. 1 and 2) whereas two genes displayed reduced transcript accumulation when compared with the NON-INOC control. Transcript accumulation of genes represented by Contig 4386_at, Contig 23697_at, Contig 21110_at, Contig 12005_at, Contig 10167_at, Contig 10168_at, Contig 4387_at, and Contig 16040_at displayed the largest differential expression at 16 HAI, the initial time point for establishment of the perihaustorial interface between fungal haustoria and host epidermal cells (Caldo et al. 2004). However, transcript accumulation represented by Contig 7517_at and Contig 15957_at steadily increased from 20 to $32 \mathrm{HAI}$, suggesting that different WRKY TF might function at different stages of the defense response (Ryu et al. 2006). All 12 of these genes exhibited expression patterns in the mla1-m508, mla6-m9472, and mla12-m66 loss- of-function mutants similar to those in lines containing Mlal, Mla6, and Mla12 wild-type alleles, respectively (data can be visualized at the PLEXdb website). Among the rice homologues of these 12 predicted HvWRKY genes, three genes (Contig 7243_at, Contig 12033_at, and Contig 23697_at) belong to group I, six genes (Contig 4386_at, Contig 4387_at, Contig 7517_at, Contig 10167_at, Contig 10168_at, and Contig 16040_at) belong to group II, and three genes (Contig 12005_at, Contig 15957_at, and Contig 21110_at) belong to group III (Table 2). In contrast, the remaining $14 \mathrm{HvWRKY}$ genes showed little change in transcript levels.

\section{HvWRKY10, HvWRKY19, and HvWRKY28 are required for $M l a$-mediated resistance to $B$. graminis f. sp. hordei.}

Next, we were interested to test whether the 12 differentially expressed $\mathrm{HvWRKY}$ genes are phenotypically associated with $M l a$-specified resistance. We utilized a DNA-bombardmentmediated Barley stripe mosaic virus (BSMV) gene-silencing system to analyze these $\mathrm{HvWRKY}$ genes in response to powdery mildew (Meng et al. 2009). GenBank accession numbers and primer sequences are shown in Supplementary Table S1. We designed primers to target unique regions of each gene, as well as the highly conserved WRKY domain. However, to prevent off-target silencing, the sequence-specific region from each gene was used for the functional analysis presented here. Inserts were amplified by reverse-transcriptase polymerase chain reaction (RT-PCR) and cloned into the PacI and NotI sites downstream of the $\gamma \mathrm{b}$ stop codon in the BSMV: $\gamma$ subgenome, driven by the Cauliflower mosaic virus $35 \mathrm{~S}$ promoter (Meng et al. 2009). Constructs were co-bombarded with BSMV: $\alpha$ and BSMV: $\beta$ into 7-day-old barley 'Black Hull-less' (CIho 2277) seedlings, which are susceptible to BSMV infection. Approximately 7 days after bombardment, typical infected first leaves display brown striping adjacent to the middle vein, and the second leaf will exhibit stripe mosaic or necrotic symp-

Table 2. Total of 26 probe sets representing HvWRKY transcription factors on the Barley1 GeneChip

\begin{tabular}{|c|c|c|c|c|}
\hline Gene number & WRKY group & Barley1 GeneChip probe set ID & AtWRKY orthologa & OsWRKY ortholog $^{\mathrm{a}}$ \\
\hline HvWRKY46 & I & Contig7243_at & 20 & 78 \\
\hline HvWRKY41 & I & Contig12033_at & * & $*$ \\
\hline HvWRKY6 & I & Contig14308_at & 1 & 82 \\
\hline HvWRKY42 & I & Contig15657 at & 2 & 80 \\
\hline HvWRKY50 & I & Contig23697_at & 33 & 24 \\
\hline HvWRKY1 & IIa & Contig4386 at & $18,40,60$ & 28,71 \\
\hline HvWRKY $^{\text {d }}$ & IIa & Contig4387_at & $18,40,60$ & 28,71 \\
\hline HvWRKY52 & IIa & EBro02_SQ004_H10_at & $18,40,60$ & 71 \\
\hline HvWRKY $47^{c}$ & $\mathrm{IIb}$ & Contig7517_at & 6,42 & 99 \\
\hline HvWRKY19 & IIc & Contig10167_at & 50 & 7 \\
\hline HvWRKY20 & IIc & Contig10168_at & 50 & 7 \\
\hline HvWRKY13 & IIc & Contig13268_at & 56 & 23 \\
\hline HvWRKY5 & IIc & Contig18462 at & 50 & 77 \\
\hline HvWRKY7 & IId & Contig7798_at & 11,17 & 68 \\
\hline HvWRKY10 & IId & Contig16040_at & $*$ & 51 \\
\hline HvWRKY9 & IId & Contig22226_at & 7 & $*$ \\
\hline HvWRKY8 & IId & Contig23011_at & 39,74 & $*$ \\
\hline HvWRKY39 & IIe & Contig13375 at & 65 & 13 \\
\hline HvWRKY45 & IIe & HVSMEa0001M23r2_at & 69 & 14 \\
\hline HvWRKY54 & IIe & EBro08 SQ008 D15 at & 35 & 37 \\
\hline HvWRKY34 & III & Contig10471_at & $*$ & 46 \\
\hline HvWRKY28 & III & Contig12005 at & $30,41,53$ & 74 \\
\hline HvWRKY33 & III & Contig15869_at & $*$ & 46 \\
\hline HvWRKY $32^{\mathrm{e}}$ & III & Contig15957 at & 54,70 & 45 \\
\hline HvWRKY4 & III & Contig20450 at & 54,70 & 47 \\
\hline HvWRKY30 & III & Contig21110_at & $30,41,53$ & 69 \\
\hline
\end{tabular}

${ }^{a}$ Adapted from Mangelsen and colleagues (2008), except the newly identified HvWRKY47, HvWRKY50, HvWRKY52, and HvWRKY54. Asterisk (*) indicates that ortholog could not be assigned with significance.

${ }^{\mathrm{b}}$ Additional Barley1 probe set that represents this gene is rbaal15j13_s_at.

${ }^{c}$ Newly annotated HvWRKY TFs in this study.

d Additional Barley1 probe sets that represent this gene are HB25K10r_at and HB25K10r_s_at.

${ }^{\mathrm{e}}$ Additional Barley 1 probe set that represents this gene is S0001000055P18F1_s_at. 
toms. Accordingly, we utilized second leaf sap, which harbors the amplified recombinant virions, to mechanically infect 7-dayold seedlings of CI 16137 (Mlal; incompatible), CI 16151 (Mla6; incompatible), and Sultan5 (Mla12; incompatible). These three genotypes were also susceptible to BSMV infection, although slightly less than the original incubator, Black Hull-less. After 12 days of silencing, plants were then inoculated with $B$. graminis f. sp. hordei $5874\left(A V R_{a 1}, A V R_{a 6}, A V R_{a 12}\right.$, and $\left.a v r_{a 13}\right)$. At least three independent biological replications were performed for each of the 12 candidate HvWRKY TF (discussed below).

After challenge with $B$. graminis f. sp. hordei 5874, we assayed the relative penetration index by fixing and staining the leaves, followed by recording the number of secondary hyphae (as an indicator of functional haustoria) in each treatment $(\mathrm{Hu}$ et al. 2009). At 4 days after inoculation (DAI), a significant increase in the number of secondary hyphae was observed for three of the 12 constructs (BSMV:WRKY10, BSMV:WRKY19, and BSMV:WRKY28) compared with BSMV:00 and nonBSMV-inoculated control plants (mock) for all three genotypes (Fig. 3; Table 3). CI 16137 (Mlal) and Sultan-5 (Mla12) backgrounds were more difficult to quantify due to the vigorous growth of mycelia tangling together on silenced leaves.

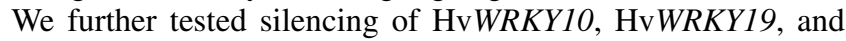
HvWRKY28 in a compatible interaction when Clansman (Mla13) was used as a host; however, no significant differences were seen in the Mla13-avr $r_{a 13}$ specified interactions. Therefore, based on the experiments presented here, HvWRKY10, HvWRKY19, and HvWRKY28 appear to act as positive regulators in defense signaling to $B$. graminis f. sp. hordei.

We also documented whether conidiation occurred on second or third leaves of silenced plants at 7 DAI. On CI 16151 (Mla6) and CI 16137 (Mlal) backgrounds, colonization of $B$. graminis f. sp. hordei was not detected on the leaf surface of either WRKY-gene silenced plants or the BSMV:00 control plants whereas, on Sultan-5 (Mla12) plant leaves, a few colonies were observed on both silenced plants and control plants. In general, the Mla6 and Mlal alleles confer rapid and absolute resistance, whereas Mla12 mediates intermediate resistance to $B$. graminis f. sp. hordei isolate 5874. Therefore, we assume that the sporulation on Sultan-5 was not due to silencing of HvWRKY10, HvWRKY19, and HvWRKY28. Thus, these HvWRKY TF likely influence the early stages of $B$. graminis f. $\mathrm{sp}$. hordei proliferation in host plants, because silencing in an $M l a$-specified incompatible interaction triggers haustoria formation and growth of elongated secondary hyphae but not the subsequent colonization on the leaf surface. These observations are consistent with results previously observed for BSMV-induced silencing of $\mathrm{HvCS}$ (Chorismate synthase), HvASa2 (Anthranilate synthase 2), and HvCM1 (Chorismate mutase 1) (Hu et al. 2009). The observed expression profiles of HvWRKY10, HvWRKY19, and HvWRKY28 also correlate with

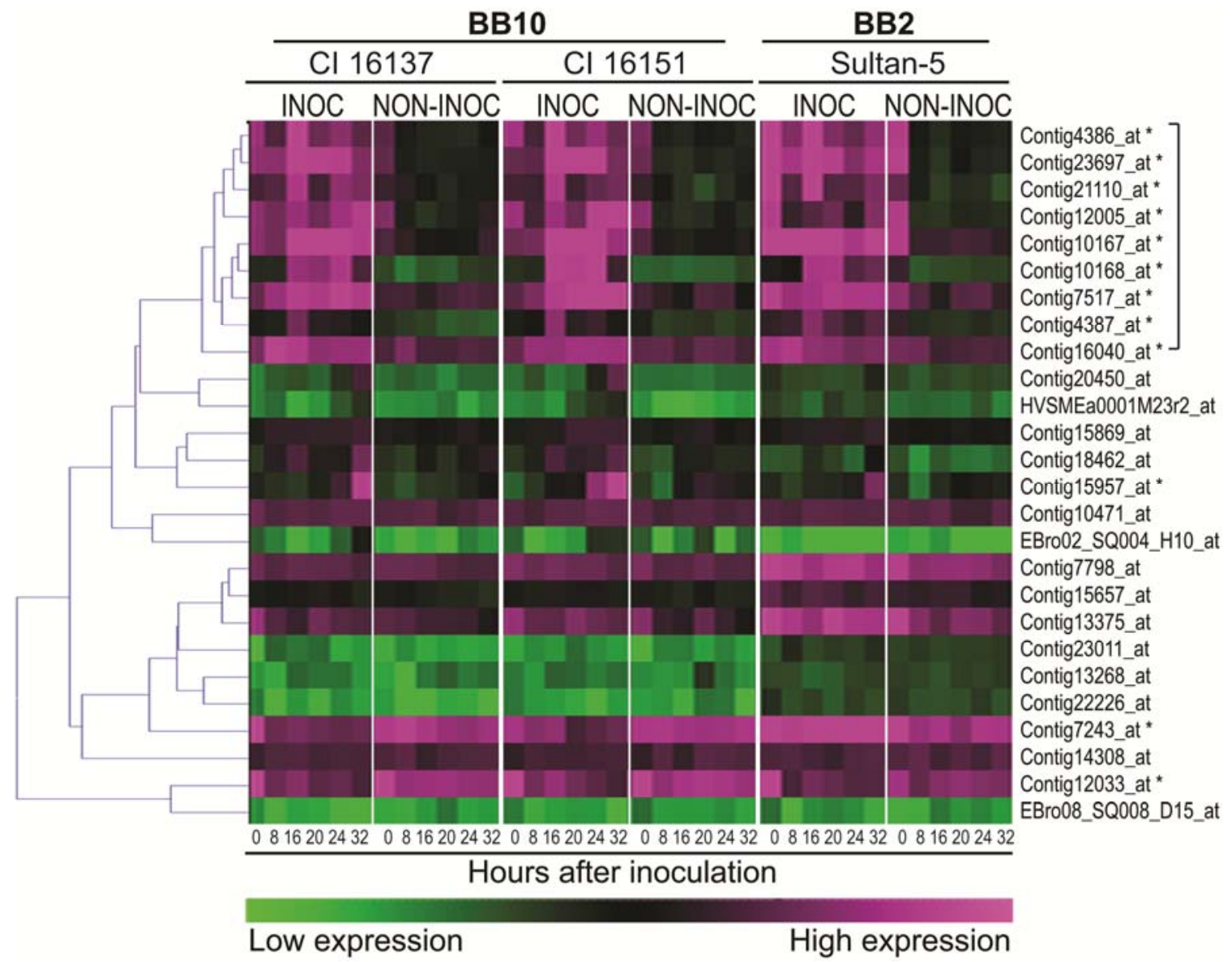

Fig. 1. Time-course expression profiles of 26 predicted barley WRKY transcription factors in barley-Blumeria graminis f. sp. hordei interactions. Data displayed are derived from PLEXdb accession BB10 (shown in the left four panels) and BB2 (shown in the right two panels) (Caldo et al. 2006; Meng et al 2009; Moscou et al. 2011). Barley plants were either inoculated with B. graminis f. sp. hordei 5874 (INOC) or without inoculation (NON-INOC). Natural $\log$ values of the mean signal intensities at each time point in CI 16137, CI 16151, and Sultan-5 were used in the cluster analysis. A data matrix was constructed with genes represented by corresponding probe sets in rows and time points of all barley genotype-B. graminis f. sp. hordei treatment combinations in columns. A Pearson correlation was used to measure similarities of transcript accumulation. Hierarchical clustering was performed with HCE 3.5 software. Probe sets marked with asterisks represent the differentially expressed genes after challenge with B. graminis f. sp. hordei (in all three genotypes); these genes were used for Barley stripe mosaic virus virus-induced gene silencing in this study. 

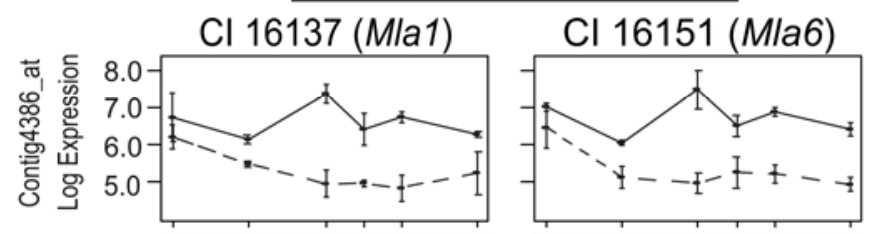

Sultan-5 (Mla12)
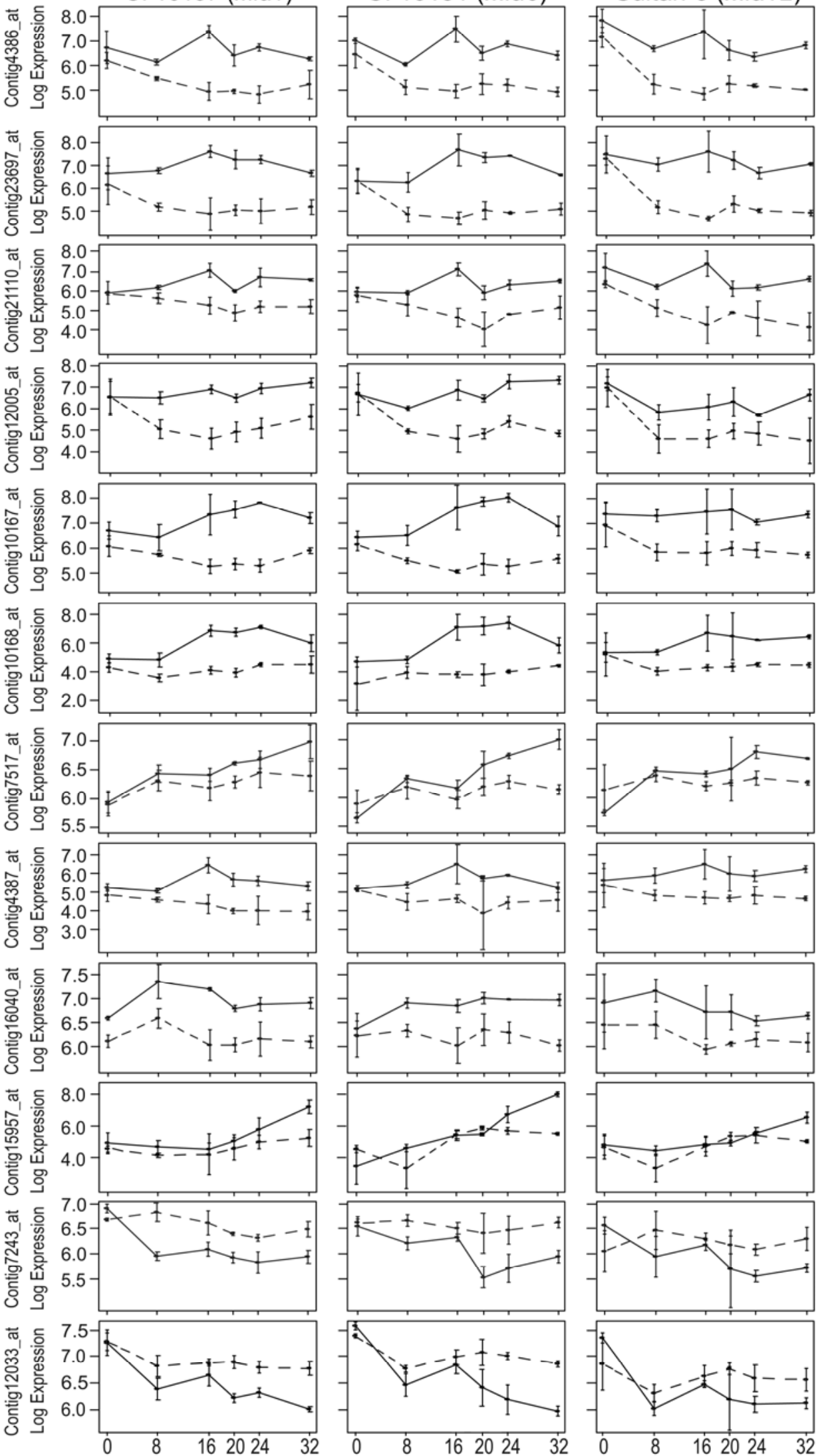

Fig. 2. Reciprocal expression profiles of 12 differentially expressed barley WRKY transcription factors in different genotype-Blumeria graminis f. sp. hordei combinations. The natural logarithm of signal intensities in CI 16137 (Mla1), CI 16151 (Mla6), and Sultan-5 (Mla12) with (solid line) or without (dashed line) B. graminis f. sp. hordei isolate 5874 treatment were plotted in graphs. Standard errors were calculated based on the mixed linear model used for analysis. 
these data, in that transcripts were highly induced up to $16 \mathrm{HAI}$ (Figs. 1 and 2), an early time point coinciding with conidiospore germination and appressorial germ tube growth.

To monitor the level of target gene silencing, relative tran-

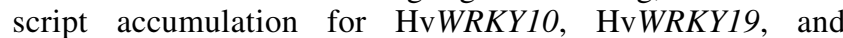
HvWRKY28 were assayed via quantitative (q)RT-PCR. Third leaves (same stage as for phenotyping) of BSMV-treated plants were sampled at 24 HAI with $B$. graminis f. sp. horde $i$ and RNA was isolated. Barley Actin mRNA was used as an internal quantitative control for all samples. A significant reduction in target transcripts was observed in infected leaves as compared with BSMV:00 control plants in all three genotypes

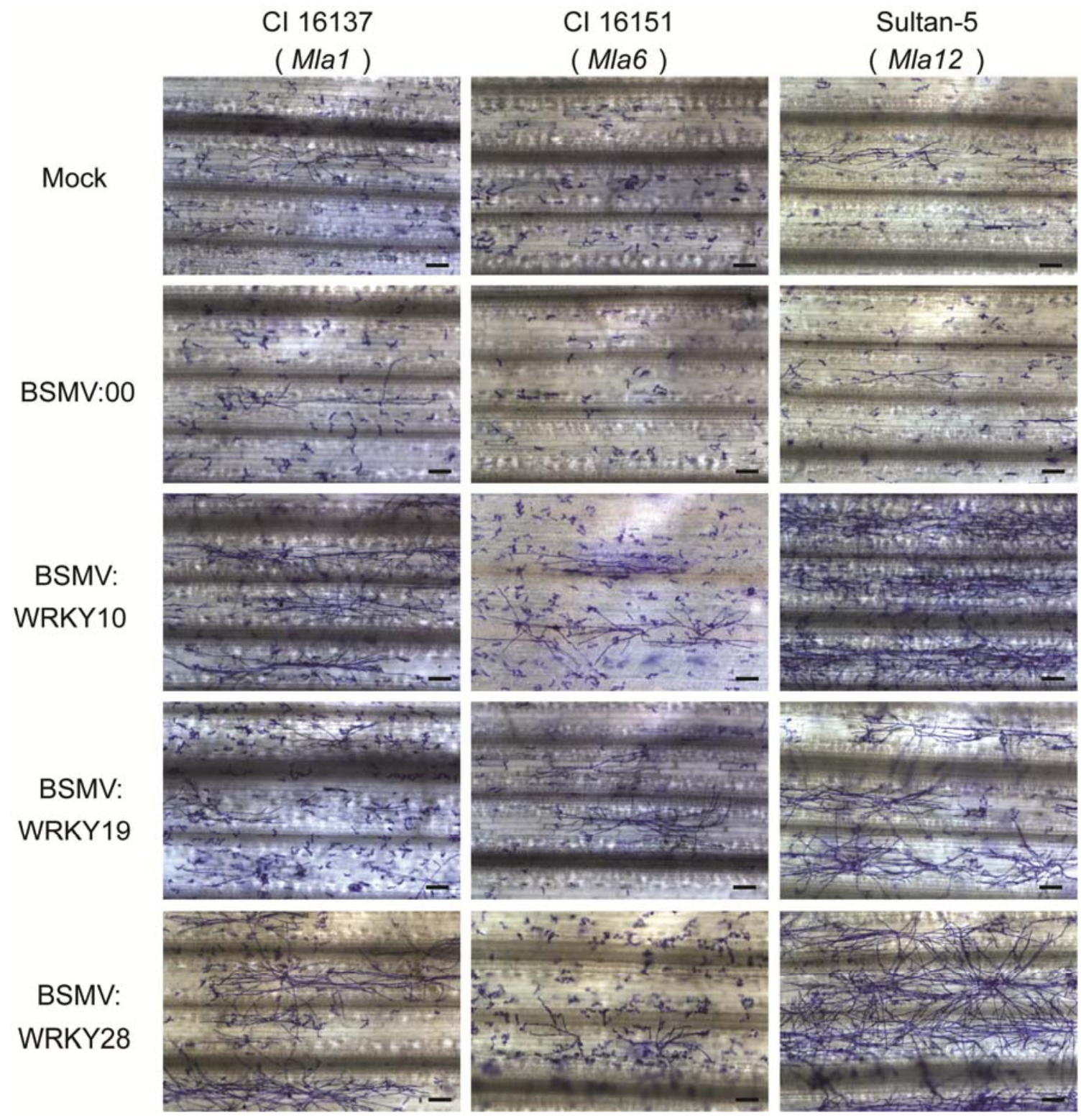

Fig. 3. Infection structures for Blumeria graminis f. sp. hordei in Barley stripe mosaic virus (BSMV) virus-induced gene silencing (VIGS) and control barley leaves. CI 16137 (Mla1), CI 16151 (Mla6), and Sultan-5 (Mla12) plants infected with BSMV-VIGS constructs and inoculated with B. graminis f. sp. hordei isolate $5874\left(A V R_{a l}, A V R_{a 6}\right.$, and $\left.A V R_{a 12}\right)$. Barley leaves were fixed at $96 \mathrm{~h}$ after inoculation (HAI). Mock was included as a non-BSMV-infected control and BSMV:00 designates the BSMV empty vector control; BSMV-VIGS constructs and controls are designated at the left lane of each row of the pictures. Horizontal bars (inset) represent $100 \mu \mathrm{m}$.

Table 3. Blumeria graminis f. sp. hordei penetration efficiency (PE) in CI 16151 (Mla6) treated with Barley stripe mosaic virus (BSMV) constructs

\begin{tabular}{lccrr}
\hline Construct & Total spores $^{\mathbf{a}}$ & With ESH $^{\mathbf{b}}$ & PE $^{\mathbf{c}}$ & $\boldsymbol{P}^{\text {value }} \mathbf{d}^{\mathbf{d}}$ \\
\hline BSMV:00 & 1,012 & 3 & 0.30 & .a. \\
BSMV:HvWRKY10 & 843 & 126 & 14.95 & $<0.001$ \\
BSMV:HvWRKY19 & 954 & 67 & 7.02 & $<0.001$ \\
BSMV:HvWRKY28 & 895 & 106 & 11.84 & $<0.001$ \\
\hline
\end{tabular}

\footnotetext{
${ }^{\text {a }}$ Total spores in the silenced region indicate the combined total of three independent experiments.

${ }^{\mathrm{b}} \mathrm{ESH}=$ elongated secondary hyphae.

${ }^{\mathrm{c}} \mathrm{PE}$ is shown as the mean of the PE from three independent replications.

${ }^{\mathrm{d}} P$ values (BSMV:00 versus others) were obtained using a generalized linear mixed model to test for a significant difference of the PE by comparing the test constructs versus the BSMV:00 control. A $P$ value $<0.05$ indicates that the PE are significantly different; n.a. $=$ not applicable.
} 
(Fig. 4). qRT-PCR was not performed for the nine WRKY proteins that did not produce a hyphal growth phenotype.

\section{Subcellular localization}

of HvWRKY10, HvWRKY19, and HvWRKY28.

As putative TF, HvWRKY10, HvWRKY19, and HvWRKY28 are likely to be localized in the nucleus. To test this, we fused
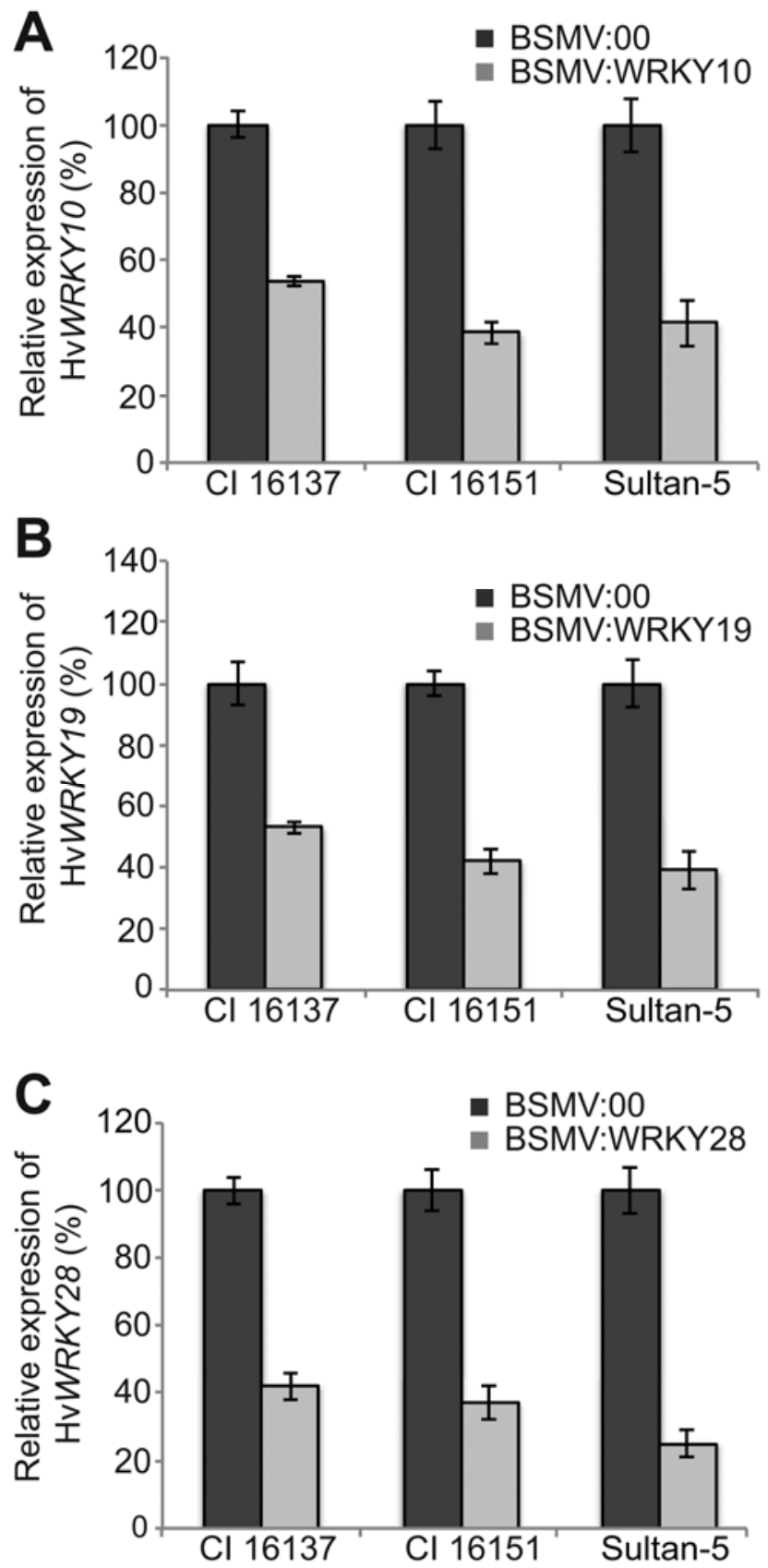

Fig. 4. Barley stripe mosaic virus (BSMV) virus-induced gene silencingmediated degradation as evidenced by quantitative reverse-transcriptase polymerase chain reaction analysis on transcript accumulation of $\mathbf{A}$, HvWRKY10; B, HvWRKY19; and C, HvWRKY28. RNA isolated from silenced third leaves of barley CI 16137 (Mlal)-, CI 16151 (Mla6)-, and Sultan-5 (Mla12)-treated BSMV:00 and BSMV silencing constructs. The amount of RNA in each reaction was normalized using primers specific for Actin. The $2^{-\Delta C T}$ method was used to calculate the target gene expression for each individual silencing construct- as compared with BSMV:00treated plants (Schmittgen and Livak 2008). Fold change due to silencing is calculated by dividing the expression mean value for the targeted WRKY gene in silenced plants by the mean value measured in BSMV:00-treated plants.

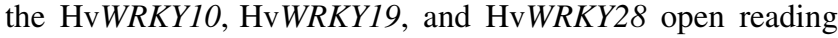
frames (ORF) with Aequorea victoria green fluorescent protein (GFP), and the maize ubiquitin promoter was used to drive the expression of the fusion proteins. Constructs were individually bombarded into barley epidermal cells. All three transiently expressed fusion proteins localized exclusively to the nuclei of barley epidermal cells (Fig. 5). By contrast, the GFP protein was found in both the nucleus and cytoplasm due to its small size (Grebenok et al. 1997). Nuclear localization of the three WRKY protein supports their roles as transcriptional regulators.

\section{Yeast two-hybrid interactions with MLA.}

HvWRKY10, HvWRKY19, and HvWRKY28 were also highly expressed after B. graminis f. sp. hordei infection on Mla mutants mlal-m508, mla6-m9472, and mla12-m66 (Fig. 6). In the absence of corresponding resistance $(R)$ gene, these three mutants are susceptible to $B$. graminis f. sp. hordei isolate 5874. This may suggest that these three HvWRKY genes function in an $R$-gene-independent manner (i.e., they might not be regulated directly by Mla). To test this hypothesis, we checked for potential interactions between HvWRKY10, HvWRKY19, and HvWRKY28 and the three Mla alleles using the Gal4 yeast co-transformation system (Clontech, Mountain View, CA, U.S.A.). HvWRKY10, HvWRKY19, and HvWRKY28 were cloned into the pray vector and Mlal, Mla6, and Mla12 were cloned into the bait vector appropriately, and each pair of plasmids was co-transformed into yeast strain Y2HGold. HvWRKY10, HvWRKY19, and HvWRKY28 were also cotransformed with constructs encoding the MLA1, MLA6, and MLA12 coiled coil (CC; amino acids 1 to 46) and CC-nucleotide binding (CC-NB; amino acids 1 to 578) domains. Specific interactions were observed in control tests with HvWRKY1 and MLA CC domain, consistent with Shen and associates (2007). However, in side-by-side assessments with the HvWRKY1 and MLA CC controls, no interaction was detected among HvWRKY10, HvWRKY19, and HvWRKY28 prey constructs and MLA, MLA CC, or MLA CC-NB encod-

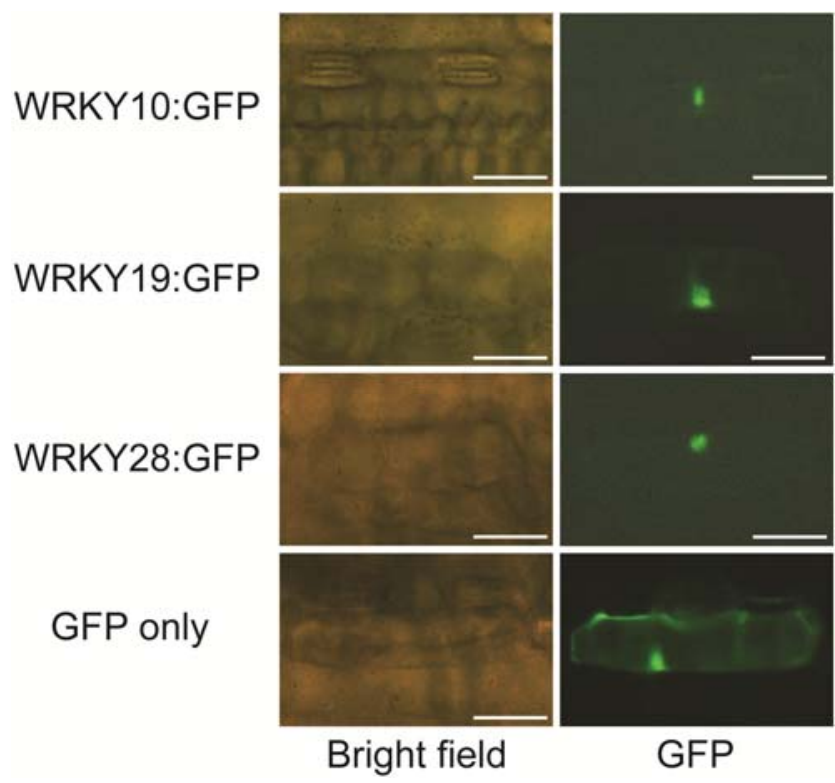

Fig. 5. Subcellular localization of HvWRKY10, HvWRKY19, and HvWRKY28. HvWRKY10, HvWRKY19, and HvWRKY28 were independently fused with green fluorescent protein (GFP). Chimeric proteins localized exclusively to the nucleus of barley epidermal cells whereas GFP alone was observed in both the nucleus and the cytoplasm due to its small size. Horizontal bars (inset) represent $100 \mu \mathrm{m}$. 
ing baits in three independent experiments (Fig. 7). These results suggest that HvWRKY10, HvWRKY19, and HvWRKY28 either do not directly interact with MLA1, MLA6, or MLA12 or that, alternatively, these genes and gene fragments do not function correctly in a yeast two-hybrid system.

\section{HvWRKY10, HvWRKY19, and HvWRKY28 are required for $m l o$-mediated basal defense.}

The barley Mlo gene encodes a seven-transmembrane protein and acts as a negative defense regulator in barley- $B$. graminis f. sp. hordei interactions (Büschges et al. 1997). Loss-of-function mlo derivatives mediate a broad-spectrum resistance to B. graminis f. sp. hordei (Jørgensen 1992). Thus, barley MLO is required by powdery mildew fungi to infect host plants; this suggests that it might be recruited by the pathogen to suppress basal defense responses (Panstruga 2005).

We overexpressed HvWRKY10, HvWRKY19, and HvWRKY28 in barley epidermal cells via an established single-cell-transient assay (Hu et al. 2009; Shirasu et al. 1999). The full-length HvWRKY10, HvWRKY19, and HvWRKY28 ORF were cloned into the vector pUbi:Nos to create the expression constructs pUbi:HvWRKY10, pUbi:HvWRKY19, and pUbi:HvWRKY28. Individual WRKY constructs were co-bombarded with the V26UMUG vector, which encodes both the $\beta$-glucuronidase (GUS) and Mlo genes, into epidermal cells of barley mlo-5 BC7 Ingrid seedlings and, subsequently, challenged with $B$. graminis f. sp. hordei isolate 5874. Control bombardments were performed with the V26UMUG reporter construct alone. In this test, GUS-marked epidermal cells are transformed to susceptibility as a result of transient wild-type Mlo expression, whereas surrounding nontransfected cells retain $m l o-5$ resistance. Fungal penetration efficiency (PE) was calculated as the ratio of GUS-marked cells exhibiting elongating secondary hyphae (ESH) to the total transformed cells attacked by $B$. graminis $\mathrm{f}$. sp. hordei (Halterman and Wise 2004; Hu et al. 2009).

Transient overexpression of pUbi:HvWRKY10, pUbi:HvWRKY19, and pUbi:HvWRKY28 significantly decreased fungal PE compared with the V26UMUG (GUS-Mlo) control ( $P$ value $<0.001)$ (Table 4). Co-expression of Mlo and WRKY genes in mlo-5 compromised fungal colony growth in Mlotransformed cells, suggesting that pUbi:HvWRKY10, pUbi: HvWRKY19, and pUbi:HvWRKY28 also play a role in barley basal defense response to $B$. graminis f. sp. hordei .

\section{DISCUSSION}

Regulation of barley defense to $B$. graminis f. sp. hordei.

WRKY proteins comprise a superfamily of TF implicated in regulating various physiological processes, including defense response to pathogens (Eulgem 2006; Eulgem and Somssich 2007; Eulgem et al. 2000; Rushton et al. 2010; Singh et al. 2002; Zhang and Wang 2005). Here, we screened 26 barley HvWRKY TF for their roles in a defense network to $B$. graminis f. sp. hordei, the causal agent of barley powdery mildew. Among them, silencing constructs targeting HvWRKY10,

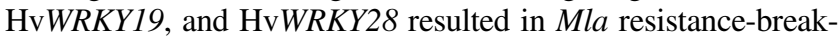

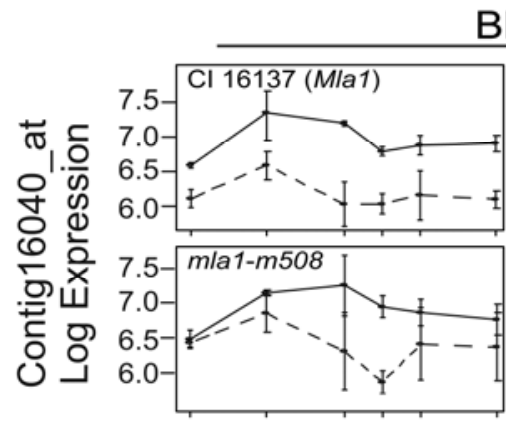

BB10
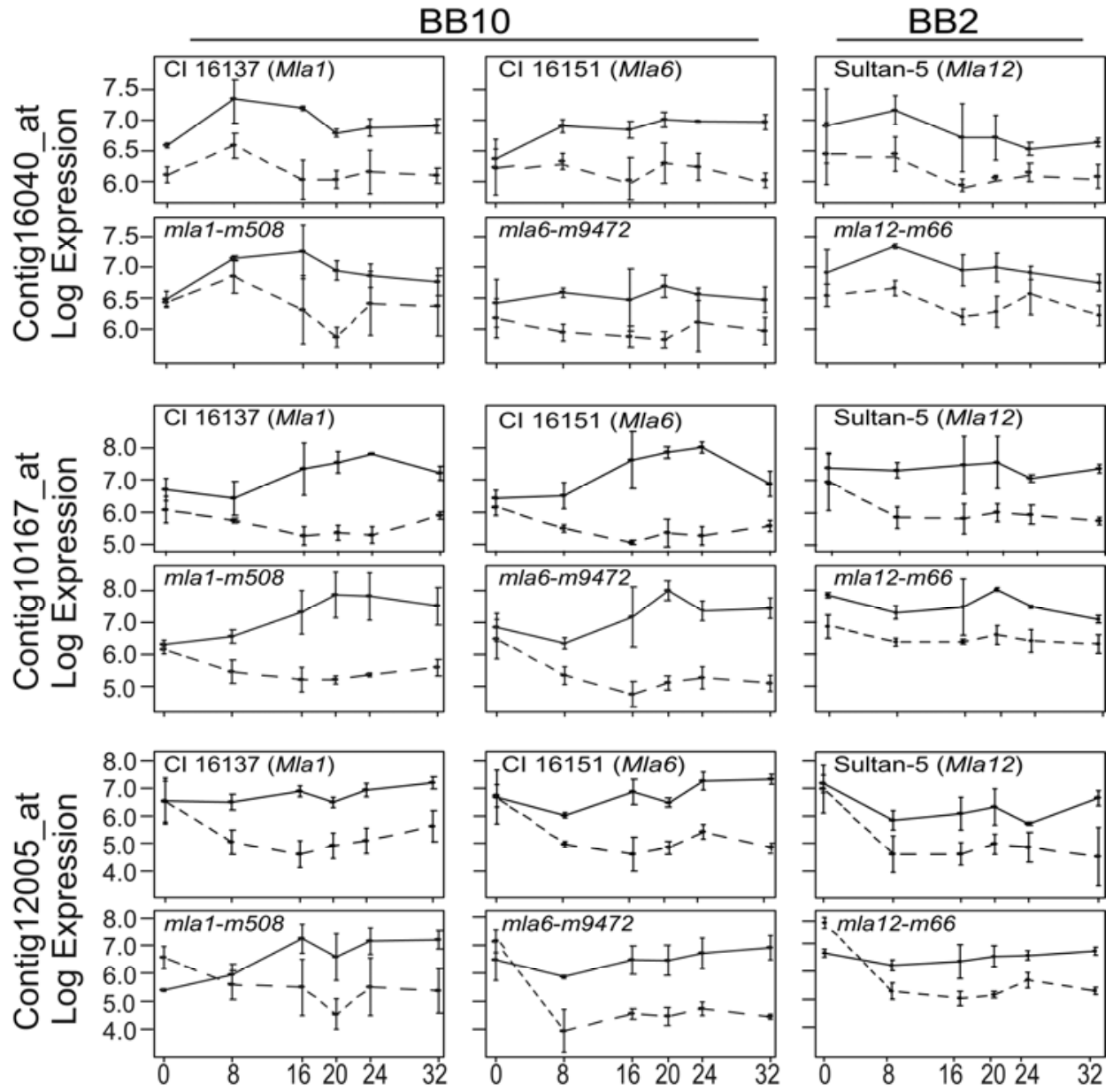

Fig. 6. Reciprocal expression profiles of three differentially expressed barley WRKY transcription factors in various genotype-Blumeria graminis f. sp. hordei treatment combinations. The natural logarithm of signal intensities in CI 16137 (Mla1), CI 16151 (Mla6), and Sultan-5 (Mla12) and their mutants with (solid line) or without (dashed line) B. graminis f. sp. hordei isolate 5874 treatment were plotted in graphs. Standard errors were calculated based on the mixed linear model used for analysis. 
ing phenotypes; consistently, overexpression of these genes suppressed Mlo-mediated susceptibility.

HvWRKY10, HvWRKY19, and HvWRKY28 belong to three different WRKY groups. HvWRKY10 is in the IId subgroup and has been shown to interact with calmodulin (CaM), a ubiquitous $\mathrm{Ca}^{2+}$-binding protein regulating diverse cellular functions by amending the activity of various target proteins in Arabidopsis (Park et al. 2005). HvWRKY19 is a member of the IIc subgroup while HvWRKY28 fits in group III (Table 2). In Arabidopsis, the majority of the WRKY group III members are responsive to both pathogen infection and salicylic acid stimulation (Kalde et al. 2003). The observation that HvWRKY10, HvWRKY19, and HvWRKY28 belong to different subgroups may point to their roles in different plant processes (Eulgem et al. 2000). Nevertheless, results reported here suggest that all three have similar roles as activators in reprogramming the defense-signaling pathway.

A potential obstacle with gene silencing is that genes sharing identity for as few as 11 contiguous nucleotides may be unintentionally silenced (Jackson et al. 2003). To avoid offtarget silencing, inserts in the silencing constructs were designed on the gene specific region. Pairwise comparison of the nucleotide sequences of HvWRKY10, HvWRKY19, and

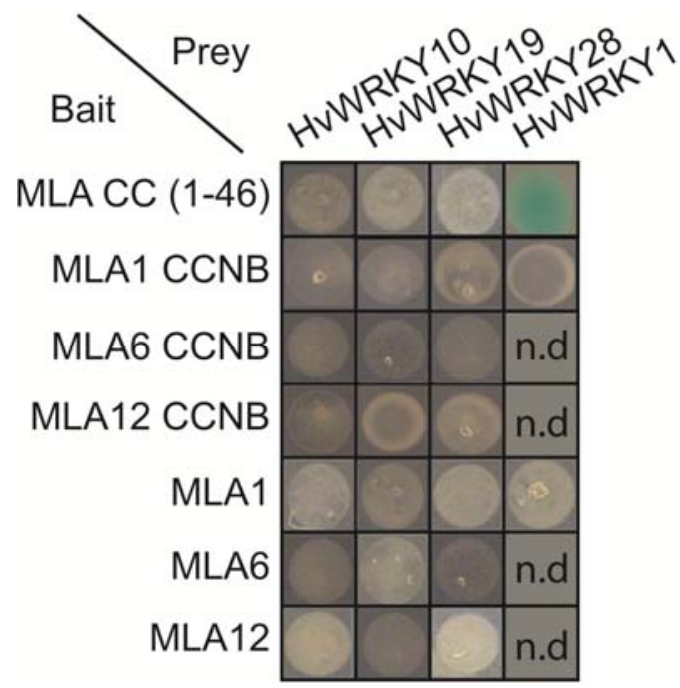

Fig. 7. Results of yeast two-hybrid assays between bait fusion-containing MLA1/6/12, MLACC, and MLA1/6/12 coiled-coil nucleotide-binding (CCNB) domains and prey fusion-comprising HvWRKY1, HvWRKY10, HvWRKY19, and HvWRKY28. Positive interaction between MLA CC (146) and HvWRKY1 (control) shown by $\alpha$-galactosidase ( $\alpha$-Gal) activity (blue color) on selective media (SD/-Leu/-Trp/X- $\alpha-G a l / A b A)$. No positive interactions were observed from all the other combinations (white colonies); n.d. $=$ not determined
HvWRKY28 showed that they do not share longer than 6-bp stretches of identity, which renders off-target silencing unlikely (Xu et al. 2006). Further analysis via comparative RNA gel blot analysis also revealed no RNA degradation for the offtarget WRKY transcripts. For example, if HvWRKY10 was silenced as the target gene, HvWRKY19 and HvWRKY28 remained intact. This was consistent for all three combinations (data not shown).

In addition to HvWRKY10, HvWRKY19, and HvWRKY28, nine $H v W R K Y$ genes are also differentially expressed upon $B$. graminis f. sp. hordei infection (Figs. 1 and 2). However, these plants retained a wild-type phenotype after silencing. We hypothesize that these genes might be co-expressed with other HvWRKY genes and act in a co-regulatory networks (Berri et al. 2009); in this case, silencing of one specific gene will have only a small effects on the resistance of the plants. Nevertheless, HvWRKY10, HvWRKY19, and HvWRKY28 might occupy the pivotal branch points on the defense signaling pathway and work autonomously as defense regulators.

\section{Layers of the plant immune system.}

Two interdependent branches of the plant immune system, PTI and ETI, sense different protein receptors and trigger subsequent defense signaling networks in response to microbes (Jones and Dangl 2006). ETI is stronger and faster than PTI, when employed by the plant to counter specific effector proteins, by means of a corresponding $R$-gene-mediated defensesignaling pathway. However, PTI and ETI seem to share common downstream signaling machinery. A largely overlapping set of plant cellular responses is triggered in both branches, including transcriptional reprogramming of gene expression (Caldo et al. 2004; Tsuda and Katagiri 2010). During this process, WRKY TF have been demonstrated to be involved in regulating both basal and R-gene-mediated defense response against pathogens (Bhattarai et al. 2010; Caldo et al. 2004; Kishor et al. 2010; Knoth et al. 2007; Peng et al. 2008).

Our interpretation of HvWRKY10, HvWRKY19, and $\mathrm{HvWRKY28}$ function is illustrated in Figure 8. Silencing of

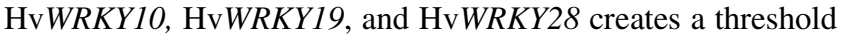
by which recognition of certain defense proteins is inhibited, thus lessening the output of an $R$-gene-mediated defense response. This would result in effector-triggered susceptibility to B. graminis f. sp. hordei. Unlike HvWRKY1 and HvWRKY2, HvWRKY10, HvWRKY19, and HvWRKY28 have no physical interaction with MLA (Shen et al. 2007). How they are associated with MLA to activate the plant immune system remains unresolved. Moreover, overexpression of HvWRKY10, HvWRKY19, and HvWRKY28 in lines carrying Mlo, which encodes a negative regulator of penetration resistance, significantly reduced plant susceptibility. In several European countries, mlo-mediated broad-spectrum resistance, which is effec-

Table 4. Blumeria graminis f. sp. hordei penetration efficiency (PE) with overexpression of HvWRKY10, HVWRKY19, HvWRKY28 and $\beta$-glucuronidase (GUS)-Mildew resistance locus o (Mlo) in mlo-5 plants

\begin{tabular}{|c|c|c|c|c|}
\hline \multirow[b]{2}{*}{ Construct } & \multicolumn{2}{|c|}{ Number of cells ${ }^{a}$} & \multirow[b]{2}{*}{$\mathbf{P E}^{\mathrm{d}}$} & \multirow[b]{2}{*}{$P$ value $^{\mathrm{e}}$} \\
\hline & Attacked $^{\text {b }}$ & 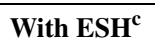 & & \\
\hline$\overline{\text { GUS-Mlo }^{f}}$ & 698 & 463 & 66.33 & n.a \\
\hline GUS-Mlo + HvWRKY10 & 951 & 482 & 50.68 & $<0.001$ \\
\hline GUS-Mlo + HvWRKY19 & 1,669 & 729 & 43.68 & $<0.001$ \\
\hline GUS-Mlo + HvWRKY28 & 1,106 & 551 & 49.82 & $<0.001$ \\
\hline
\end{tabular}

\footnotetext{
${ }^{a}$ Raw numbers indicate the combined total of three independent experiments.

${ }^{\mathrm{b}}$ Attacked with B. graminis f. sp. hordei.

${ }^{c} \mathrm{ESH}=$ elongated secondary hyphae.

${ }^{\mathrm{d}} \mathrm{PE}$ is shown as the mean of the PE from three independent replications.

${ }^{\text {e }} P$ values (GUS-Mlo versus others) were obtained using a generalized linear mixed model to test for a significant difference of the PE by comparing the test constructs versus the GUS-Mlo control. A $P$ value $<0.05$ indicates that the PE are significantly different; n.a. $=$ not applicable.

${ }^{\mathrm{f}}$ Control GUS-Mlo construct was co-bombarded with the overexpression empty vector to obtain a more equivalence with other treatments.
} 
tive against all isolates of $B$. graminis $\mathrm{f}$. sp. hordei, has been cultivated extensively (Jørgensen 1992). In the absence of

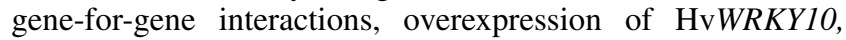

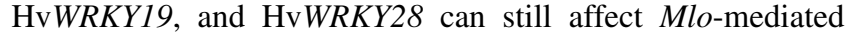
susceptibility. This implies that overexpression of HvWRKY10,

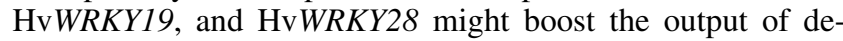
fense gene expression and, thus, halt fungal growth. Because PTI is more ancient than ETI, the involvement of HvWRKY10, HvWRKY19, and HvWRKY28 in R-gene-mediated resistance may have been recruited from their original function in basal defense (Bhattarai et al. 2010; Jones and Dangl 2006).

\section{Potential roles in other biological processes.}

WRKY TF might have functional roles in controlling several seemingly disparate processes. For instance, HvWRKY1/38 has regulatory roles in both biotic and abiotic stress responses. HvWRKY1/38 negatively regulates basal defense against barley powdery mildew; however, it is also involved in the cold and drought stress response (Eckey et al. 2004; Marè et al. 2004; Shen et al. 2007). The putative ortholog of HvWRKY10 in rice is OsWRKY51, which shares 79\% amino acid identity. Abscissic-acid (ABA) inducible OsWRKY51 physically interacts with OsWRKY71, both involved in gibberellin (GA)-regulated MYB class transcription factor (GAMYB) signaling in aleurone cells and, thus, play roles in ABA and GA signaling and cross-talk (Xie et al. 2006). Interestingly, the putative ortholog of OsWRKY71 in barley is HvWRKY1, which is a negative regulator in barley defense to B. graminis f. sp. hordei (Shen et al. 2007). This poses the question: is it possible that HvWRKY10 and HvWRKY1 physically interact in the process of regulating the defense response? This question remains to be tested.
OsWRKY7 is the closest ortholog of HvWRKY19 in rice; they share $64 \%$ identity at the amino acid level. OsWRKY7 is highly induced upon infection by the fungal pathogen $M$. grisea, the causal agent of rice blast disease. After challenging with bacteria pathogen $X$. oryzae pv. oryzae, OsWRKY7 is also differentially expressed (Ryu et al. 2006). The closest HvWRKY28 ortholog in Arabidopsis is AtWRKY41 which, upon overexpression, displayed enhanced resistance to wild-type Pseudomonas syringae pv. tomato DC3000 but increased susceptibility to Erwinia carotovora $\mathrm{EC1}$ (Higashi et al. 2008).

These studies imply that HvWRKY10, HvWRKY19, and HvWRKY28 might have other roles in plant biological processes. Indeed, analysis of Barley1 GeneChip data (accessions BB49, BB9 and BB61) (PLEXdb) revealed that all three $\mathrm{HvWRKY}$ genes were highly induced after challenge with the stem rust fungus Puccinia graminis f. sp. tritici (Zhang et al. 2008b) whereas only HvWRKY19 was highly induced when infected with Fusarium graminearum, causal agent of $\mathrm{Fu}-$ sarium head blight of barley (Boddu et al. 2006). When wild barley (H. vulgare subsp. spontaneum) accession 'Shechem 12-32' was inoculated with $P$. hordei and Cochliobolus sativus, causal agents of leaf rust and spot blotch, respectively (Millett et al. 2009), all three $\operatorname{HvWRKY}$ genes were also highly induced. Nevertheless, the comprehensive function of HvWRKY10, HvWRKY19, and HvWRKY28 in these specific fungus-barley interactions remains to be characterized.

\section{Conclusions.}

A balanced defense response prevents plants from overexpression of specific outputs, thus limiting damage to target cells (Dangl 2007). This appropriate response requires a deli-

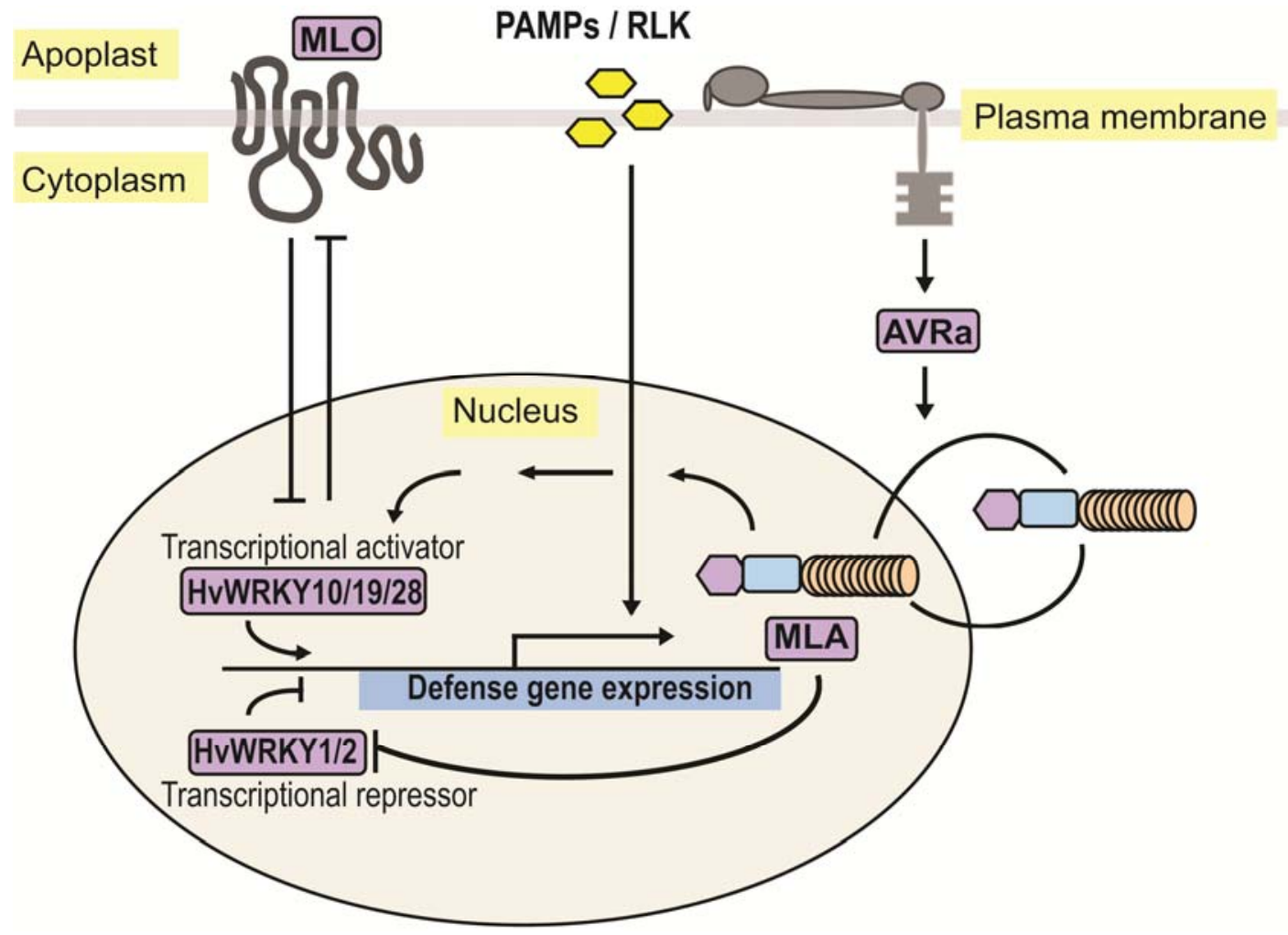

Fig. 8. Model for the functional prediction of HvWRKY10, HvWRKY19, and HvWRKY28 in the barley immune system. In this model, HvWRKY10, HvWRKY19, and HvWRKY28 act as transcriptional activators by regulating the output of defense gene expression in basal defense; overexpression of HvWRKY10, HvWRKY19, and HvWRKY28 can significantly reduce the Mlo-mediated susceptibility (left). Unlike HvWRKY1 and HvWRKY2, HvWRKY10, HvWRKY19, and HvWRKY28 do not appear to directly interact with MLA; however, they are essential in resistance-gene-mediated signaling, because gene silencing resulted in increased susceptibility to Blumeria graminis f. sp. hordei, which presents pathogen-associated molecular patterns (PAMPs) or avirulence effectors (right). In both cases, HvWRKY10, HvWRKY19, and HvWRKY28 are essential in a delicate regulation pathway to potentiate the expression of defense genes to achieve a balanced defense. 
cate regulatory system; many WRKY TF are involved in regulating this process in the nucleus, and exhibit a vital function in fine-tuning the defense response upon pathogen invasion. HvWRKY10, HvWRKY19, and HvWRKY28 are such examples, which have precise roles in integrated plant defense networks.

\section{MATERIALS AND METHODS}

Plant material, growth conditions, and fungal isolates.

Seedlings of barley lines CI 16151 (Mla6), CI 16137 (Mlal), Sultan-5 (Mla12), Clansman (Mla13), CIho 2277 (Black Hullless), and mlo-5 BC7 Ingrid were grown in a temperature-controlled greenhouse with supplemental lighting. Following BSMV virus-induced gene silencing (VIGS) bombardment or mechanical inoculation, plants were transferred to a temperature-controlled growth chamber with a 16-h photoperiod, with light intensity ranging from 400 to $1,000 \mu \mathrm{mol} \mathrm{m} \mathrm{m}^{-2} \mathrm{~s}^{-1}$, and day and night temperatures 24 and $20^{\circ} \mathrm{C}$, respectively. B. graminis f. sp. hordei isolate $5874\left(A V R_{a 1}, A V R_{a 6}\right.$, and $\left.A V R_{a 12}\right)$ was propagated on $H$. vulgare 'Manchuria' (CI 2330) in a controlled growth chamber at $18^{\circ} \mathrm{C}$ (16 h of light and $8 \mathrm{~h}$ of darkness).

\section{Expression profiling and analysis.}

Datasets BB2 (ArrayExpress E-TABM-82) and BB10 (ArrayExpress E-TABM-142) in PLEXdb were used to analyze the 26 HvWRKY genes in response to powdery mildew (Caldo et al. 2006; Dash et al. 2012; Meng et al. 2009; Shen et al. 2005). RNA was extracted from 7-day-old seedling first leaves (PO:0007094) harvested at 0, 8, 16, 20, 24, and 32 HAI with $B$. graminis f. sp. hordei isolate $5874\left(A V R_{a 6}\right)$ (Moscou et al. 2011). Noninoculated plants at these six time points were used as controls. The analysis presented here was based on six genotypes $\times$ six time points $\times$ two inoculation treatments $\times$ three biological replications for a total of 216 GeneChip hybridizations.

FDR was calculated using the histogram-based technique as described by Nettleton and colleagues (2006). FDR was controlled at $0.01 \%$ among inoculated and noninoculated plants for at least one time point throughout all six genotypes, respectively. Hierarchical clustering was performed with HCE 3.5 software (University of Maryland, College Park). A Pearson correlation was used to measure similarities of transcript accumulation.

\section{$B S M V$-mediated gene silencing.}

Total RNA was extracted from CI 16151 (Mla6) plants challenged at $20 \mathrm{HAI}$ with $B$. graminis f. sp. hordei isolate 5874 $\left(A V R_{a 6}\right)$ using Trizol agent (Caldo et al. 2004). First-strand cDNA was synthesized using $2 \mu \mathrm{g}$ of total RNA, oligo $(\mathrm{dT})_{20}$ primer, and SuperScript III Reverse Transcriptase (Invitrogen, Carlsbad, CA, U.S.A.). Subsequently, first-strand cDNA was used as the template to amplify each silencing targeted gene fragment. Amplified PCR fragments each contained an introduced PacI and NotI recognition sites at the $5^{\prime}$ and $3^{\prime}$ ends, respectively. PCR products then were digested with $P a c \mathrm{I}$ and NotI and ligated into the PacI and NotI sites of BSMV: $\gamma$. DNA bombardment and subsequent virion mechanical infection was performed according to Meng and associates (2009).

Twelve days after mechanical infection, plants displayed a BSMV infection phenotype (i.e., a brown stripe on the first leaf and stripe mosaic or necrosis on the second and third leaves). Whole plants were then inoculated with fresh $\mathrm{B}$. graminis f. sp. hordei conidiospores and placed in an $18^{\circ} \mathrm{C}$ growth chamber (16 h of light and $8 \mathrm{~h}$ of darkness). B. graminis $\mathrm{f}$. sp. hordei infection types were scored at 7 DAI. Although it is possible that an overlap in general defense gene functions induced by BSMV may interfere with $B$. graminis f. sp. hordei development in barley, a recent investigation has shown that it does not affect the infection of $B$. graminis $\mathrm{f}$. sp. tritici, the causal agent of powdery mildew in wheat (Tufan et al. 2011).

Along with the whole-plant inoculation, segments from the bottom half of five second leaves were placed on $0.6 \%$ phyto agar (Duchefa, Haarlem, The Netherlands) medium and then inoculated with fresh B. graminis f. sp. hordei conidiospores. For the convenience of counting the conidiospores, inoculum was applied to give approximately 2,000 spores $/ \mathrm{cm}^{2}$. Detached leaves were stained and scored microscopically at 4 DAI. The staining process was performed according to Hein and associates (2005), with minor modifications. Leaves were fixed for $24 \mathrm{~h}$ on filter paper soaked with 1:1 ( $\mathrm{vol} / \mathrm{vol})$ ethanol/acetic acid and for $48 \mathrm{~h}$ on filter paper soaked with lactoglycerol (1:1:1 [vol/vol] lactic acid/glycerol $/ \mathrm{H}_{2} \mathrm{O}$ ) and stained with $0.05 \%$ (wt/vol) Coomassie brilliant blue R-250 stain in 50\% methanol and $10 \%$ acetic acid. A Zeiss Axio Imager M.1 microscope (Zeiss, Inc., Thornwood, NY, U.S.A.) was used for observation.

Three treatments of interest-BSMV:HvWRKY10 (Trt-1), BSMV:HvWRKY19 (Trt-2), and BSMV:HvWRKY28 (Trt-3)as well as the BSMV:00 control were applied to leaves to assay their effect on the growth of secondary hyphae. In each of three replications, five leaves were exposed under each of the four treatments. On each leaf, the number of secondary hyphae and the total number of spores were counted. A generalized linear mixed model was used, fit to the data. In the model, we assume that the number of secondary hyphae on each leaf has a binomial distribution, with number of trials equal to the total number of spores on the leaf. The logit of each binomial success probability was modeled as a linear function of fixed treatment effects and normally distributed replication effects. An overdispersion parameter was included to model variation among leaves within each treatment and replication.

\section{Quantitative real-time PCR.}

Each individual construct-treated plant was considered a silencing event; the third leaves of three individual BSMVVIGS-treated and three BSMV:00 vector control treated seedlings were collected after $24 \mathrm{~h}$ of $B$. graminis f. sp. hordei inoculation. Total RNA was extracted using Trizol-like reagent (Caldo et al. 2004); RNase-free DNase I (Ambion, Austin, TX, U.S.A.) then was utilized to remove the genomic DNA. Firststrand cDNA was synthesized using $2 \mu \mathrm{g}$ of total RNA oligo(dT $)_{20}$ primer by using SuperScript III reverse transcriptase (Invitrogen). To ensure that only the endogenous gene was amplified, gene-specific primers were designed independently beyond the insert fragment region in the silencing constructs. PCR reactions were run in an ICycler (Bio-Rad, Hercules, CA, U.S.A.) using PerfeCTa SYBR Green FastMix for iQ (Quanta Biosciences, Gaithersburg, MD, U.S.A.). Cycling conditions were as follows: $3 \mathrm{~min}$ at $95^{\circ} \mathrm{C}$; followed by 40 cycles of $15 \mathrm{~s}$ at $95^{\circ} \mathrm{C}$ and $1 \mathrm{~min}$ at $60^{\circ} \mathrm{C}$; then followed by 80 cycles of $10 \mathrm{~s}$ at $55^{\circ} \mathrm{C}$, with increasing set point temperature after cycle 2 by $0.5^{\circ} \mathrm{C}$ for collection and analysis of melting curve data. The PCR program and quantification of the relative changes in gene expression were conducted according to the protocol described by Schmittgen and Livak (2008). Barley Actin was used as internal control. The $2^{-\Delta \mathrm{CT}}$ method was used to calculate the target gene expression in individual silencing constructtreated and BSMV:00-treated plants; the fold change due to silencing was presented by dividing the expression mean value for targeted $W R K Y$ gene in silenced plants by the mean value measured in BSMV:00-treated plants (Schmittgen and Livak 2008).

\section{Subcellular localization.}

HvWRKY-GFP fusion constructs were synthesized by amplifying the respective HvWRKY ORF from the transient overex- 
pression vectors. The amplified PCR product contained the HvWRKY gene ORF without a stop codon and with an introduced HindIII and BamHI recognition sites at the $5^{\prime}$ and $3^{\prime}$ ends, respectively. The PCR product was then digested with HindIII and BamHI and was ligated to the N terminus of GFP within the Ubi:GFP vector (Nielsen et al. 1999). The HvWRKYGFP chimeric gene constructs were introduced into barley epidermal cells by using biolistic PDS-1000/he system (Bio-Rad). Gold particles (Bio-Rad) were coated with plasmid and delivered into 7-day-old seedling detached leaves of barley CI 16151 (Mla6) using 900-psi rupture disks. As a negative control for the localization of the HvWRKY-GFP fusion protein, Ubi:GFP vector alone was also independently transformed into barley leaves. The GFP protein was visualized with a Zeiss Axioplan II fluorescence microscope (Zeiss, Inc.).

\section{Yeast two-hybrid analysis.}

The BD Matchmaker library construction and screening kit (Clontech) was adapted to detect the protein in vitro interaction between HvWRKY10, HvWRKY19, and HvWRKY28 and MLA. CI 16151 (Mlab), CI16137 (Mlal), and Sultan-5 (Mla12) cDNA were synthesized from RNA extracted from plant seedling leaves at $20 \mathrm{HAI}$ with $B$. graminis f. sp. hordei isolate 5874 by using SuperScript III reverse transcriptase (Invitrogen). The full-length ORF of HvWRKY10, HvWRKY19, HvWRKY28, and HvWRKY1 and barley Mla1, Mla6, and Mla12 were amplified from barley cDNA. The CC (amino acids 1 to 46) and CC-NB (amino acids 1 to 578) domains from MLA1, MLA6, and MLA12 were also amplified from barley cDNA. PCR products from $\mathrm{HvWRKY}$ were subsequently cloned into GAL4 activation domain of pGADT7 vector and PCR products from $M l a$ were subsequently cloned into DNA binding domain (BD) of pGBKT7 vector. Co-transformation to yeast strain and subsequent analyses were performed as described in Clontech protocols.

\section{Transient overexpression.}

The full-length ORF of HvWRKY10 (GenBank accession DQ840409), HvWRKY28 (GenBank accession DQ863112), and HvWRKY19 (GenBank accession DQ840418) were amplified from barley CI $16151 \mathrm{cDNA}$, which was synthesized from RNA extracted from seedlings at $20 \mathrm{HAI}$ with $B$. graminis $\mathrm{f}$. sp. hordei isolate 5874. EcoRV and HindIII were used to double digest the PCR product, which was then inserted into the expression vector pUbi:Nos, which was also digested with the same enzymes. The newly constructed vector, pUbi:WRKY, was cobombarded with V26UMUG into barley mlo-5 BC7 Ingrid epidermal cells in three independent experiments (Halterman and Wise 2004; Shirasu et al. 1999). GUS and Coomassie blue staining were performed as described previously (Hu et al. 2009). Scoring for susceptibility was performed under light microcopy by calculating the ratio of GUS-marked cells to the total GUS cells with ESH by B. graminis f. sp. hordei.

In this transient overexpression assay, three treatments of interest-Ubi:HvWRKY10 + GUS/Mlo (Trt-1), Ubi:HvWRKY19 + GUS/Mlo (Trt-2), and Ubi:HvWRKY28 + GUS/Mlo (Trt-3) and a control treatment were applied to leaves in order to demonstrate their effect on the growth of secondary hyphae. In each of three replications, five to six leaves were exposed under each of the four treatments. On each leaf, the number of secondary hyphae and the total number of spores were counted. A generalized linear mixed model was fit to the data. In the model, we assume that the number of secondary hyphae on each leaf has a binomial distribution, with number of trials equal to the total number of spores on the leaf. The logit of each binomial success probability was modeled as a linear function of fixed treatment effects and normally distributed replication effects. An over-dispersion parameter was included to model variation among leaves within each treatment and replication.

\section{ACKNOWLEDGMENTS}

We thank K. Sato and T. Matsumoto for access to barley full-length cDNA data prior to publication; M. J. Moscou, R. Caldo, and P. Surana for bioinformatics of the WRKY family and for initial analysis of GeneChip data; R. Xu and D. Nettleton for statistical analysis; D. Mistry, F. Guimaraes, and T. Hewezi for technical advice; G. Fuerst for excellent technical assistance throughout the project; and $\mathrm{W}$. Xu for critical review of the manuscript. This research was supported by National Science Foundation Plant Genome grant 05-00461 and 09-22746. This article is a joint contribution of the Iowa Agriculture and Home Economics Experiment Station and the Crop and Insect Genetics, Genomics and Informatics Research Unit, United States Department of Agriculture-Agricultural Research Service. Y. Meng designed the research, performed research, contributed new analytic tools, and analyzed data, and wrote the article. R. P. Wise designed the research, performed research and analyzed data, and wrote the article.

\section{LITERATURE CITED}

Berri, S., Abbruscato, P., Faivre-Rampant, O., Brasileiro, C. A., Fumasoni, I. Satoh, K., Kikuchi, S., Mizzi, L., Morandini, P., Pè, E., and Piffanelli, P. 2009. Characterization of WRKY co-regulatory networks in rice and Arabidopsis. BMC Plant Biol. 9:120.

Bhattarai, K. K., Atamian, H. S., Kaloshian, I., and Eulgem, T. 2010. WRKY72-type transcription factors contribute to basal immunity in tomato and Arabidopsis as well as gene-for-gene resistance mediated by the tomato $R$ gene $M i-1$. Plant J. 63:229-240.

Boddu, J., Cho, S., Kruger, W. M., and Muehlbauer, G. J. 2006. Transcriptome analysis of the barley-Fusarium graminearum interaction. Mol Plant-Microbe Interact. 19:407-417.

Büschges, R., Hollricher, K., Panstruga, R., Simons, G., Wolter, M., Frijters, A., van Daelen, R., van der Lee, T., Diergaarde, P., Groenendijk, J., Töpsch, S., Vos, P., Salamini, F., and Schulze-Lefert, P. 1997. The barley Mlo Gene: A novel control element of plant pathogen resistance. Cell 88:695-705.

Caldo, R. A., Nettleton, D., and Wise, R. P. 2004. Interaction-dependent gene expression in $M l a$-specified response to barley powdery mildew. Plant Cell 16:2514-2528.

Caldo, R. A., Nettleton, D., Peng, J., and Wise, R. P. 2006. Stage-specific suppression of basal defense discriminates barley plants containing fastand delayed-acting Mla powdery mildew resistance alleles. Mol. PlantMicrobe Interact. 19:939-947.

Chen, L., Zhang, L., and Yu, D. 2010. Wounding-induced WRKY8 is involved in basal defense in Arabidopsis. Mol. Plant-Microbe Interact. 23:558-565.

Chen, W., Provart, N. J., Glazebrook, J., Katagiri, F., Chang, H.-S., Eulgem, T., Mauch, F., Luan, S., Zou, G., Whitham, S. A., Budworth, P. R., Tao, Y., Xie, Z., Chen, X., Lam, S., Kreps, J. A., Harper, J. F., SiAmmour, A., Mauch-Mani, B., Heinlein, M., Kobayashi, K., Hohn, T., Dangl, J. L., Wang, X., and Zhu, T. 2002. Expression profile matrix of Arabidopsis transcription factor genes suggests their putative functions in response to environmental stresses. Plant Cell 14:559-574.

Close, T. J., Wanamaker, S., Caldo, R. A., Turner, S. M., Ashlock, D. A., Dickerson, J. A., Wing, R. A., Muehlbauer, G. J., Kleinhofs, A., and Wise, R. P. 2004. A new resource for cereal genomics: 22K Barley GeneChip comes of age. Plant Physiol. 134:960-968.

Dangl, J. L. 2007. Nibbling at the plant cell nucleus. Science 315:10881089.

Dash, S., Van H., J., Hong, L., Wise, R. P., and Dickerson, J. A. 2012. PLEXdb: Gene expression resources for plants and plant pathogens. Nucleic Acids Res. 40:D1194-D1201.

Dellagi, A., Helibronn, J., Avrova, A. O., Montesano, M., Palva, E. T., Stewart, H. E., Toth, I. K., Cooke, D. E., Lyon, G. D., and Birch, P. R. 2000. A potato gene encoding a WRKY-like transcription factor is induced in interactions with Erwinia carotovora subsp. atroseptica and Phytophthora infestans and is coregulated with class I endochitinase expression. Mol. Plant-Microbe Interact. 13:1092-1101.

Dong, J., Chen, C., and Chen, Z. 2003. Expression profiles of the Arabidopsis WRKY gene superfamily during plant defense response. Plant Mol. Biol. 51:21-37.

Eckey, C., Korell, M., Leib, K., Biedenkopf, D., Jansen, C., Langen, G., and Kogel, K.-H. 2004. Identification of powdery mildew-induced barley genes by cDNA-AFLP: Functional assessment of an early expressed MAP kinase. Plant Mol. Biol. 55:1-15. 
Eulgem, T. 2006. Dissecting the WRKY web of plant defense regulators. PLoS Pathog. 2:e126.

Eulgem, T., and Somssich, I. E. 2007. Networks of WRKY transcription factors in defense signaling. Curr. Opin. Plant Biol. 10:366-371.

Eulgem, T., Rushton, P. J., Robatzek, S., and Somssich, I. E. 2000. The WRKY superfamily of plant transcription factors. Trends Plant Sci. 5:199-206.

Grebenok, R. J., Pierson, E., Lambert, G. M., Gong, F., Afonso, C. L., Haldeman-Cahill, R., Carrington, J. C., and Galbraith, D. W. 1997. Greenfluorescent protein fusions for efficient characterization of nuclear targeting. Plant J. 11:573-586.

Halterman, D. A., and Wise, R. P. 2004. A single-amino acid substitution in the sixth leucine-rich repeat of barley MLA6 and MLA13 alleviates dependence on RAR1 for disease resistance signaling. Plant J. 38:215-226.

Hein, I., Barciszewska-Pacak, M., Hrubikova, K., Williamson, S., Dinesen, M., Soenderby, I. E., Sundar, S., Jarmolowski, A., Shirasu, K., and Lacomme, C. 2005. Virus-induced gene silencing-based functional characterization of genes associated with powdery mildew resistance in barley. Plant Physiol. 138:2155-2164.

Higashi, K., Ishiga, Y., Inagaki, Y., Toyoda, K., Shiraishi, T., and Ichinose, Y. 2008. Modulation of defense signal transduction by flagellin-induced WRKY41 transcription factor in Arabidopsis thaliana. Molecular Genetics and Genomics 279:303-312.

Hu, P., Meng, Y., and Wise, R. P. 2009. Functional contribution of chorismate synthase, anthranilate synthase, and chorismate mutase to penetration resistance in barley-powdery mildew interactions. Mol. PlantMicrobe Interact. 22:311-320.

Jackson, A. L., Bartz, S. R., Schelter, J., Kobayashi, S. V., Burchard, J., Mao, M., Li, B., Cavet, G., and Linsley, P. S. 2003. Expression profiling reveals off-target gene regulation by RNAi. Nat. Biotechnol. 21:635637.

Jones, J. D. G., and Dangl, J. L. 2006. The plant immune system. Nature 444:323-329.

Jørgensen, I. H. 1992. Discovery, characterization and exploitation of Mlo powdery mildew resistance in barley. Euphytica 63:141-152.

Kalde, M., Barth, M., Somssich, I. E., and Lippok, B. 2003. Members of the Arabidopsis WRKY group III transcription factors are part of different plant defense signaling pathways. Mol. Plant-Microbe Interact. 16:295-305

Kishor, K. B., Hagop, S. A., Isgouhi, K., and Thomas, E. 2010. WRKY72type transcription factors contribute to basal immunity in tomato and Arabidopsis as well as gene-for-gene resistance mediated by the tomato $R$ gene Mi-1. Plant J. 63:229-240.

Knoth, C., Ringler, J., Dangl, J. L., and Eulgem, T. 2007. Arabidopsis WRKY70 is required for full RPP4-mediated disease resistance and basal defense against Hyaloperonospora parasitica. Mol. PlantMicrobe Interact. 20:120-128.

Liu, X., Bai, X., Wang, X., and Chu, C. 2007. OsWRKY71, a rice transcription factor, is involved in rice defense response. J. Plant Physiol. 164:969-979.

Mangelsen, E., Kilian, J., Berendzen, K., Kolukisaoglu, U., Harter, K., Jansson, C., and Wanke, D. 2008. Phylogenetic and comparative gene expression analysis of barley (Hordeum vulgare) WRKY transcription factor family reveals putatively retained functions between monocots and dicots. BMC Genomics 9. Published online.

Mao, P., Duan, M., Wei, C., and Li, Y. 2007. WRKY62 transcription factor acts downstream of cytosolic NPR1 and negatively regulates jasmonateresponsive gene expression. Plant Cell Physiol. 48:833-842.

Marè, C., Mazzucotelli, E., Crosatti, C., Francia, E., Stanca, A. M., and Cattivelli, L. 2004. Hv-WRKY38: A new transcription factor involved in cold- and drought-response in barley. Plant Mol. Biol. 55:399-416.

Matsumoto, T., Tanaka, T., Sakai, H., Amano, N., Kanamori, H., Kurita, K., Kikuta, A., Kamiya, K., Yamamoto, M., Ikawa, H., Fujii, N., Hori, K., Itoh, T., and Sato, K. 2011. Comprehensive sequence analysis of 24,783 barley full-length cDNAs derived from 12 clone libraries. Plant Physiol. 156:20-28.

Mayer, K. F. X., Martis, M., Hedley, P. E., Šimková, H., Liu, H., Morris, J. A., Steuernagel, B., Taudien, S., Roessner, S., Gundlach, H., Kubaláková, M., Suchánková, P., Murat, F., Felder, M., Nussbaumer, T., Graner, A., Salse, J., Endo, T., Sakai, H., Tanaka, T., Itoh, T., Sato, K., Platzer, M., Matsumoto, T., Scholz, U., Doležel, J., Waugh, R., and Stein, N. 2011. Unlocking the barley genome by chromosomal and comparative genomics. Plant Cell 23:1249-1263.

Meng, Y., Moscou, M. J., and Wise, R. P. 2009. Blufensin1 negatively impacts basal defense in response to barley powdery mildew. Plant Physiol. 149:271-285.

Millett, B. P., Xiong, Y., Dahl, S. K., Steffenson, B. J., and Muehlbauer, G. J. 2009. Wild barley accumulates distinct sets of transcripts in response to pathogens of different trophic lifestyles. Physiol. Mol. Plant Pathol. 74:91-98.
Moscou, M. J., Lauter, N., Caldo, R. A., Nettleton, D., and Wise, R. P. 2011. Quantitative and temporal definition of the Mla transcriptional regulon during barley-powdery mildew interactions. Mol. PlantMicrobe Interact. 24:694-705.

Nettleton, D., Hwang, J. T. G., Caldo, R. A., and Wise, R. P. 2006. Estimating the number of true null hypotheses from a histogram of $\mathrm{P}$ values. J. Agric. Biol. Environ. Stat. 11:337-356.

Nielsen, K., Olsen, O., and Oliver, R. 1999. A transient expression system to assay putative antifungal genes on powdery mildew infected barley leaves. Physiol. Mol. Plant Pathol. 54:1-12.

Pandey, A. K., Yang, C., Zhang, C., Graham, M. A., Horstman, H. D., Lee, Y., Zabotina, O. A., Hill, J. H., Pedley, K. F., and Whitham, S. A. 2011. Functional analysis of the Asian soybean rust resistance pathway mediated by Rpp2. Mol. Plant-Microbe Interact. 24:194-206.

Panstruga, R. 2005. Serpentine plant MLO proteins as entry portals for powdery mildew fungi. Biochem. Soc. Trans. 33:389-392.

Park, C. J., Shin, Y. C., Lee, B. J., Kim, K. J., Kim, J. K., and Paek, K. H. 2006. A hot pepper gene encoding WRKY transcription factor is induced during hypersensitive response to Tobacco mosaic virus and Xanthomonas campestris. Planta 223:168-179.

Park, C. Y., Lee, J. H., Yoo, J. H., Moon, B. C., Choi, M. S., Kang, Y. H., Lee, S. M., Kim, H. S., Kang, K. Y., Chung, W. S., Lim, C. O., and Cho, M. J. 2005. WRKY group IId transcription factors interact with calmodulin. FEBS (Fed. Eur. Biochem. Soc.) Lett. 579:1545-1550.

Peng, Y., Bartley, L. E., Chen, X., Dardick, C., Chern, M., Ruan, R., Canlas, P. E., and Ronald, P. C. 2008. OsWRKY62 is a negative regulator of basal and Xa21-mediated defense against Xanthomonas oryzae pv. oryzae in rice. Mol. Plant 1:446-458.

Qiu, D., Xiao, J., Ding, X., Xiong, M., Cai, M., Cao, Y., Li, X., Xu, C., and Wang, S. 2007. OsWRKY13 mediates rice disease resistance by regulating defense-related genes in salicylate- and jasmonate-dependent signaling. Mol. Plant-Microbe Interact. 20:492-499.

Ramamoorthy, R., Jiang, S., Kumar, N., Venkatesh, P. N., and Ramachandran, S. 2008. A comprehensive transcriptional profiling of the $W R K Y$ gene family in rice under various abiotic and phytohormone treatments. Plant Cell Physiol. 49:865-879.

Riechmann, J. L., Heard, J., Martin, G., Reuber, L., Jiang, C.-Z., Keddie, J., Adam, L., Pineda, O., Ratcliffe, O. J., Samaha, R. R., Creelman, R., Pilgrim, M., Broun, P., Zhang, J. Z., Ghandehari, D., Sherman, B. K., and Yu, G.-L. 2000. Arabidopsis transcription factors: Genome-wide comparative analysis among eukaryotes. Science 290:2105-2110.

Rushton, P. J., Somssich, I. E., Ringler, P., and Shen, Q. J. 2010. WRKY transcription factors. Trends Plant Sci. 15:247-258.

Ryu, H. S., Han, M., Lee, S. K., Cho, J. I., Ryoo, N., Heu, S., Lee, Y. H., Bhoo, S. H., Wang, G. L., Hahn, T. R., and Jeon, J. S. 2006. A comprehensive expression analysis of the $W R K Y$ gene superfamily in rice plants during defense response. Plant Cell Rep. 25:836-847.

Schmittgen, T. D., and Livak, K. J. 2008. Analyzing real-time PCR data by the comparative CT method. Nat. Protocols 3:1101-1108.

Schulte, D., Close, T. J., Graner, A., Langridge, P., Matsumoto, T. Muehlbauer, G. J., Sato, K., Schulman, A. H., Waugh, R., Wise, R. P., and Stein, N. 2009. The international barley sequencing consortium-a the threshold of efficient access to the barley genome. Plant Physiol. 149:142-147

Shen, L., Gong, J., Caldo, R. A., Nettleton, D., Cook, D., Wise, R. P., and Dickerson, J. A. 2005. BarleyBase-an expression profiling database for plant genomics. Nucleic Acids Res. 33:D614-D618.

Shen, Q., Saijo, Y., Mauch, S., Biskup, C., Bieri, S., Keller, B., Seki, H., Ulker, B., Somssich, I. E., and Schulze-Lefert, P. 2007. Nuclear activity of MLA immune receptors links isolate-specific and basal diseaseresistance responses. Science 315:1098-1103.

Shirasu, K., Nielsen, K., Piffanelli, P., Oliver, R., and Schulze-Lefert, P. 1999. Cell-autonomous complementation of mlo resistance using a biolistic transient expression system. Plant J. 17:293-299.

Singh, K. B., Foley, R. C., and Oñate-Sánchez, L. 2002. Transcription factors in plant defense and stress responses. Curr. Opin. Plant Biol. 5:430436.

Tao, Z., Liu, H., Qiu, D., Zhou, Y., Li, X., Xu, C., and Wang, S. 2009. A pair of allelic $W R K Y$ genes play opposite roles in rice-bacteria interactions. Plant Physiol. 151:936-948.

Tsuda, K., and Katagiri, F. 2010. Comparing signaling mechanisms engaged in pattern-triggered and effector-triggered immunity. Curr. Opin. Plant Biol. 13:459-465.

Tufan, H. A., Stefanato F. L., Mcgrann, G. R., MacCormack, R., and Boyd, L. A. 2011. The Barley stripe mosaic virus system used for virusinduced gene silencing in cereals differentially affects susceptibility to fungal pathogens in wheat. J. Plant Physiol. 168:990-994.

Wu, K. L., Guo, Z. J., Wang, H. H., and Li, J. 2005. The WRKY family of transcription factors in rice and Arabidopsis and their origins. DNA Res. 12:9-26. 
Xi, L., Moscou, M. J., Meng, Y., Xu, W., Caldo, R. A., Shaver, M., Nettleton, D., and Wise, R. P. 2009. Transcript-based cloning of RRP46, a regulator of rRNA processing and $R$ gene-independent cell death in barleypowdery mildew interactions. Plant Cell 21:3280-3295.

Xie, Z., Zhang, Z. L., Zou, X., Huang, J., Ruas, P., Thompson, D., and Shen, Q. J. 2005. Annotations and functional analyses of the rice WRKY gene superfamily reveal positive and negative regulators of abscisic acid signaling in aleurone cells. Plant Physiol. 137:176-189.

Xie, Z., Zhang, Z. L., Zou, X., Yang, G., Komatsu, S., and Shen, Q. J. 2006. Interactions of two abscisic-acid induced $W R K Y$ genes in repressing gibberellin signaling in aleurone cells. Plant J. 46:231-242.

Xing, D., Lai, Z., Zheng, Z., Vinod, K. M., Fan, B., and Chen, Z. 2008. Stress- and pathogen-induced Arabidopsis WRKY48 is a transcriptional activator that represses plant basal defense. Mol. Plant 1:459-470.

Xu, P., Zhang, Y., Kang, L., Roossinck, M. J., and Mysore, K. S. 2006. Computational estimation and experimental verification of off-target silencing during posttranscriptional gene silencing in plants. Plant Physiol. 142:429-440.

Yu, D., Chen, C., and Chen, Z. 2001. Evidence for an important role of WRKY DNA binding proteins in the regulation of NPRl gene expression. Plant Cell 13:1527-1540.

Zhang, J., Peng, Y., and Guo, Z. 2008a. Constitutive expression of patho- gen-inducible $O s W R K Y 31$ enhances disease resistance and affects root growth and auxin response in transgenic rice plants. Cell Res. 18:508521.

Zhang, L., Castell-Miller, C., Dahl, S., Steffenson, B., and Kleinhofs, A. 2008b. Parallel expression profiling of barley-stem rust interactions. Funct. Integr. Genomics 8:187-198.

Zhang, Y., and Wang, L. 2005. The WRKY transcription factor superfamily: Its origin in eukaryotes and expansion in plants. BMC Evol. Biol. $5: 1$

Zhou, F., Kurth, J., Wei, F., Elliott, C., Valè, G., Yahiaoui, N., Keller, B., Somerville, S., Wise, R. P., and Schulze-Lefert, P. 2001. Cell-autonomous expression of barley Mlal confers race-specific resistance to the powdery mildew fungus via a Rarl-independent signaling pathway. Plant Cell 13:337-350.

\section{AUTHOR-RECOMMENDED INTERNET RESOURCES}

HarvEST database: harvest.ucr.edu

Hierarchical Clustering Explorer software: www.cs.umd.edu/hcil/hce International Barley Sequencing Consortium webpage: barleygenome.org PLEXdb, Plant Expression database: www.plexdb.org/index.php 